NBER WORKING PAPER SERIES

\title{
SMALL BUSINESS SURVIVAL CAPABILITIES AND POLICY EFFECTIVENESS: EVIDENCE FROM OAKLAND
}

\author{
Robert P. Bartlett III \\ Adair Morse \\ Working Paper 27629 \\ http://www.nber.org/papers/w27629 \\ NATIONAL BUREAU OF ECONOMIC RESEARCH \\ 1050 Massachusetts Avenue \\ Cambridge, MA 02138 \\ July 2020
}

We extend our thanks to the staff of the City of Oakland, whose foresight in implementing the survey used in this paper and their countless hours of work on it are a testament to the desire to support the people and small businesses of Oakland. Particular thanks go to Marisa Raya. We also want to thank the SafeGraph and HomeBase companies who have generously shared their data to for research related to COVID-19's impact on U.S. businesses. Finally, we thank Annette Vissing-Jorgensen for feedback and the Berkeley Center for Law and Business for support. The views expressed herein are those of the authors and do not necessarily reflect the views of the National Bureau of Economic Research.

NBER working papers are circulated for discussion and comment purposes. They have not been peer-reviewed or been subject to the review by the NBER Board of Directors that accompanies official NBER publications.

(C) 2020 by Robert P. Bartlett III and Adair Morse. All rights reserved. Short sections of text, not to exceed two paragraphs, may be quoted without explicit permission provided that full credit, including $(\odot)$ notice, is given to the source. 
Small Business Survival Capabilities and Policy Effectiveness: Evidence from Oakland Robert P. Bartlett III and Adair Morse

NBER Working Paper No. 27629

July 2020

JEL No. E61,G38,H32,J65,L26

\begin{abstract}
$\underline{\text { ABSTRACT }}$
Using unique City of Oakland data during COVID-19, we document that small business survival capabilities vary by firm size as a function of revenue resiliency, labor flexibility, and committed costs. Nonemployer businesses rely on low cost structures to survive $73 \%$ declines in own-store foot traffic. Microbusinesses (1-to-5 employees) depend on 14\% greater revenue resiliency. Enterprises (6-to-50 employees) have twice-as-much labor flexibility, but face 11\%-to-22\% higher residual closure risk from committed costs. Finally, inconsistent with the spirit of ChettyFriedman-Hendren-Sterner (2020) and Granja-Makridis-Yannelis-Zwick (2020), PPP application success increased medium-run survival probability by $20.5 \%$, but only for microbusinesses, arguing for size-targeting of policies.
\end{abstract}

Robert P. Bartlett III

890 Simon Hall

University of California at Berkeley

Berkeley, CA 94720

rbartlett@law.berkeley.edu

Adair Morse

University of California, Berkeley

545 Student Services Bldg, \#1900

Berkeley, CA 94720

and NBER

morse@ haas.berkeley.edu 


\section{INTRODUCTION}

In the United States, small businesses encompass 25.7 million nonemployer firms, 5.8 million microbusinesses (1-5 employees) and 2.8 million larger small business enterprises (6-100 workers), together accounting for $44 \%$ of U.S. employment and $99 \%$ of firms. ${ }^{1}$ It is not news that this sector has been devastated by the nationwide curtailment of economic activity during the COVID-19 pandemic. What is perhaps novel is the idea that these 34 million businesses are heterogeneous in their toolkits to adapt to business cycle fluctuations in a very simple way - by firm size. Such a heterogeneity implies that a onesize-fits-all policy approach in a time of crisis is likely suboptimal.

In this paper, we analyze the role of the employment size of a small business in survival, working through mechanisms of revenue resiliency, labor flexibility, and committed costs. These results build on the emerging literature examining the economic consequences of the COVID-19 pandemic on the small businesses sector. For example, Bartik, Bertrand, Cullen, Glaeser, Luca, and Stanton, (2020); Humphries, Neilson, and Ulyssa (2020); and Adams, Boneva, Golin, and Rauh (2020) document many of the patterns of distress within the sector, including the high incidence of both temporary closures and mass layoffs, speaking to subjects we also study in the setting of Oakland, California. Our evidence, however, changes the perspective to survival mechanisms and adds to this body of work by analyzing the capabilities of survival by firm size. ${ }^{2}$

We then examine the compatibility of these different survival capabilities with alternative small business assistance policies - working capital loans, labor cost subsidies, and lease/debt payment restructuring programs.

Our final analysis tests for the effectiveness of the Payroll Protection Program (PPP) and Pandemic Unemployment Insurance (PUI) for small businesses and business owners with respect to short and medium-run survival. In this regard, we build on the PPP employment outcome evidence in Chetty, Friedman, Hendren, Sterner (2020) and Granja, Makridis, Yannelis, and Zwick (2020), the PPP short-term firm survival analysis in Granja, et al. (2020), and the PUI household outcome evidence in Bhutta, Blair, Dettling, and Moo (2020) and Iverson, Kluender, Wang, and Yang (2020). To our knowledge, we are the first to offer evidence that the PPP has been effective in the medium-run for survival. Importantly this result holds for microbusinesses employing fewer than 5 employees, but not for larger small businesses having between six and fifty employees (what we refer to as “enterprises”). The mechanism of this result -

\footnotetext{
${ }^{1} 2015$ and 2017 U.S. Census Data. https://www.census.gov/programs-surveys/susb/technicaldocumentation/methodology.html

${ }^{2}$ We build off the important literature on employment size being important in understanding growth and risk in small businesses (Davis, Haltiwanger, and Schuh, 1996; Davis, Haltiwanger, Jarmin, Krizan, Miranda, Nucci, and Sandusky, 2007; Haltiwanger, Jarmin, and Miranda. 2013; Decker, Haltiwanger, Jarmin, and Miranda, 2014; Mayer, Siegel, and Wright, 2018). Our contribution extends why firm size matters to a perspective on survival and policy.
} 
microbusinesses have less flexible labor costs in a downturn and thus benefit from a labor subsidy - emerges from our micro-evidence on survival capabilities.

Our empirical contributions are cast in a novel framework whereby small businesses facing an adverse macro shock face survival as a function of their endowment of (i) revenue resiliency, (ii) labor cost flexibility, and (iii) committed costs (e.g., lease and loan payments). We illustrate here the importance of these dimensions in our main findings using a stylized, previewing example involving three restaurants. The first is a nonemployer bakery, where the owner does everything. The second is a taqueria, with a total employee base of four people, each able to handle all core functions. The third is a growing pizza restaurant, employing five cooks and twenty wait staff in total.

In this stylized illustration, the macro shock causes large revenue reductions for the high-volume pizza restaurant, but the owner can easily scale back employees, as only a few employees (the cooks) provide the essential service. ${ }^{3}$ This labor flexibility does not put the owner at ease, however, because large committed costs (e.g., a large commercial lease and capital loans) loom. For instance, Bartik et al. (2020) find that, among survey respondents, the median business had expenses of over $\$ 10,000$ per month but only enough cash on hand to last for two weeks.

At the other end of firm size, the bakery owner has no labor flexibility, but bears no labor cost, other than her own sustenance. Like most nonemployers, the baker has little growth expectations and low operating margins, implying that she has low committed costs. Thus, whether or not the bakery can withstand the shock depends on her personal saving and personal utility. ${ }^{4}$

The taqueria, unlike the pizza restaurant, has very constrained labor flexibility since the decision to lay off a cook (at the core of the production) would be tantamount to closing. On committed costs, the taqueria owner is likely to be similar to the nonemployer in having kept committed costs low because its small (but vital) labor force implies that it too has low growth expectations. Yet, the strain of paying employees forces the taqueria to look for ways to maintain sufficient revenue to continue in operation, a tough setting that requires innovation aided only by having more than one core employee to assist in this endeavor.

\footnotetext{
${ }^{3}$ U.S. workers are typically "at will" employees and can be terminated at any time regardless of employee performance. Nor do federal or state laws requiring advance notice of layoffs apply to businesses having only a few dozen or fewer employees. For instance, the federal Worker Adjustment and Retraining Notification (WARN) Act requires all U.S. employers to provide at least 60 days advance notice before a mass layoff, a plant closure or a major relocation, but it applies only to employers having more than 100 employees. Similar exemptions apply under state laws imposing analogous notice requirements to employers operating within a state. For instance, the California WARN Act exempts businesses that have employed fewer than seventy-five (75) California employees in the past twelve (12) months.

4 Many nonemployers operate at a loss (Hurst and Pugsley (2011); and in IRS 2017 data (https://www.irs.gov/statistics/soi-tax-stats-nonfarm-sole-proprietorship-statistics). These proprietors who must operate at a loss may not view her business as failing. Moskowitz and Vissing-Jorgensen (2002) and Hurst and Pugsley (2011) show that nonemployers exhibit behavior consistent with the consumption of non-monetary utility in the running of their businesses.
} 
Our empirical contributions emerge out of analyses across four datasets. First are two unique survey datasets obtained from approximately one thousand small businesses located in Oakland, California. Second, we hand-collected a dataset of Oakland small business responses to the shelter-in-place order, codifying which businesses remained fully open, scaled down to a reduced or variant revenue model, temporarily closed, and permanently closed as of the last week of April, 2020. Third, we use foot traffic data from SafeGraph, covering consumer visitation data from mobile devices. Finally, we use labor data for small businesses obtained from HomeBase.

Our first analyses test revenue resiliency by firm size. Within the Oakland survey, businesses across the board reported a dramatic drop in year-over-year revenues for March 2020; however, we find notable differences based on firm size, even after controlling for revenue relevant characteristics such as location, whether the business was essential under the shelter-in-place order, industry fixed effects, and year-overyear revenues for the prior month. Overall, enterprises experienced the largest percentage decline in revenues, followed by nonemployer firms. Although struggling, microbusinesses fared the best, experiencing a revenue decline that was roughly $14 \%$ lower than that of enterprises. We obtain remarkably similar results when we use SafeGraph foot traffic data as a measure of revenue-generating patrons. In a difference-in-difference estimation with firm fixed-effects, we estimate that, relative to January levels, enterprises and nonemployers experienced a $73.8 \%$ and $73.1 \%$ drop in foot traffic in the weeks following the shelter-in-place order. Microbusinesses fared slightly better, experiencing a $68.4 \%$ decline, suggesting again that microbusiness were able to avoid roughly $14 \%$ of the drop felt by enterprises.

Our second series of analyses tests whether labor flexibility differs by firm size. Focusing first on the Oakland survey data, we find that layoffs of full-time workers and part-time workers had elasticities to firm size (based on pre-crisis employee headcount) of 0.127 and 0.172 , respectively, again controlling for location effects, whether the business was essential under the shelter-in-place order, industry fixed effects, as well as March revenue losses. Putting these estimates into the context of our stylized example, they indicate that enterprises laid off approximately $38 \%$ of full-time workers and $50 \%$ of part-time workers. In contrast, microbusinesses exhibited roughly half the labor flexibility of enterprises, laying off approximately $18 \%$ and $24 \%$ of their full- and part-time workers, respectively.

We supplement these survey estimates of labor flexibility using HomeBase data. In a differences-indifferences estimation with firm and week fixed effects, we estimate the elasticity of post-crisis employee counts and payrolls to firms' pre-crisis employee headcount, controlling for revenue declines. We find elasticities of post-crisis labor to pre-crisis worker counts ranging from -0.25 to -0.30 , nationally and in Oakland. Translating these findings into our classification of firms, we find that during the pandemic, enterprises were able to cut back payrolls 55.1 percent, while microbusinesses cut back only 37.1 percent, or two-thirds the reduction of enterprises. 
Third, we investigate the role of committed costs in a firm's survival across different sized firms. We base our estimates on respondent's self-reported probability of having to close permanently, taking residual closure variation as a proxy for committed costs once we level firms on revenue resiliency and labor flexibility. We find that closure risk is increasing in worker counts. In particular, relative to microbusinesses and nonemployers, enterprises face a respective $11 \%$ and $22 \%$ higher closure risk due to committed costs. These results are consistent with larger small businesses incurring greater committed costs as they expand operations, but unlike labor, these costs are less flexible, making them a primary source of closure risk for growth-oriented small businesses.

We then map these findings to the design of small business disaster assistance, both in the context of COVID-19 and in other periods of local and national macroeconomic distress. Our mapping puts a framing on a set of simple intuitions. Working capital loan programs to small businesses (such as conventional disaster loans offered by the Small Business Administration (SBA)) require revenue resilience mechanisms to be at work, which at least in the short term would be most effective on microbusinesses and then nonemployers. Conversely, programs offering subsidies to restructure debt, leases, or other committed costs would be most effective on survival odds for larger enterprises. Lastly, labor cost-oriented grant and subsidy programs would be most effective for microbusinesses and nonemployers, who cannot depend on labor flexibility for survival, since the labor force consists of core employees.

Consider, for example, the landmark PPP implemented as part of the Coronavirus Aid, Relief, and Economic Security (CARES) Act in March 2020. The PPP authorizes the expenditure of nearly \$610 billion in small business loans. As suggested by its name, PPP loans were intended to subsidize labor, and the original terms of the program provided that loans could be forgiven entirely if a business spends at least $75 \%$ of loan proceeds to maintain pre-crisis payrolls in the first eight weeks following loan disbursement. But given our findings regarding labor flexibility, this subsidy sits uncomfortably with the survival capabilities of larger enterprises who may have little need for a labor subsidy given their ability to scale back labor to match reduced revenues. Consistent with this observation, Chetty et al. (2020) find that the PPP failed to spur employment among businesses receiving a PPP loan. Their sample, however, did not include microbusinesses, for which a labor subsidy may have been more useful under our framework.

To explore this possibility, we turn to the second Oakland survey-a follow-up survey conducted in June 2020 that focused specifically on the aid that Oakland small businesses had pursued as well as their short-term and medium-term projections for survival. Of particular interest is utilization of PPP loans and the PUI authorized by the CARES Act. Both programs represent a labor subsidy insofar that they were intended to cover labor costs for employer and nonemployer businesses. As such, they should be especially useful for those businesses that continue operations but are limited in their ability to scale down labor costs. 
Our setup to study the effects of the PPP and PUI on survival is subject to concerns about selection. However, with regard to the PPP, we are aided by the design of the Oakland survey and the evidence and insights in Granja, Makridis, Yannelis, and Zwick (2020). The Oakland survey asks whether an owner applied for each program, allowing the answer to be No, Yes - Successfully, or Yes - Unsuccessfully. Because there were little-to-no financial or economic eligibility criteria for the PPP (other than providing attestations), Granja et al. (2020)'s first stage test shows convincingly that the lack of success largely results from bank frictions. Thus, we can use the applying-for the PPP variables to control for selection and study the effect of the PPP under the idea that the Granja et al. (2020) insight holds in our sample.

We find results consistent with the intuition in our framework and the labor flexibility results. Relative to firms that were unsuccessful in applying for PPP funding, those who successfully applied reported a 20.5\% greater probability of being able to survive beyond six months. This result, however, is confined to nonemployers and microbusinesses, consistent with these firms' inflexible labor structures. Due to the important role of these businesses within the national economy, this finding suggests the PPP has been beneficial for stakeholders in the vast majority of small businesses in the country. For instance, according to 2015 census data, $92.9 \%$ of businesses and $17 \%$ of employment are in businesses under 20 employees. Nonemployer owners that utilized the PUI also reported a lower likelihood of having to close their businesses in the short-term—but not the medium term—consistent with nonemployers using this shortterm labor subsidy (which expires in July 2020) to avoid searching for alternative sources of personal income, thus averting an immediate closure of their establishments.

Overall, our findings have critical implications for the design of assistance programs, especially when combined with the established welfare effects of different sized small businesses. Decker, Haltiwanger, Jarmin, and Miranda (2014) show that among small businesses, only those with greater than five employees create future job growth past the formative years. That the PPP was most effective as a survival program for nonemployers and microbusinesses may accordingly concern those who saw the program as an aid to future job growth. ${ }^{5}$

Conversely, the PPP might be assessed more favorably among those viewing the program through a welfare lens that prioritizes the needs of community economic stakeholders. The evidence in Hurst and Pugsley (2010) and Austin, Glaeser and Summers (2018) documents how nonemployers and microbusinesses critically support local communities through the maintenance of vibrancy in commercial districts. Community vibrancy directly maps to welfare through spatial spillovers to governments and other

\footnotetext{
${ }^{5}$ Evidence of these concerns appears in the modification of the PPP by Congress in June 2020. Not surprisingly, following the enactment of the PPP, a chorus of small business owners complained that the PPP forgiveness requirement that $75 \%$ of loan processed be spent on payroll was ill-suited for their survival plans, causing them to pass on the program (Freedman 2020). In response, Congress amended the program to decrease the required payroll spend to $60 \%$ of loan proceeds and to allow it to be accomplished over a 24 -week period rather than an 8-week period.
} 
community stakeholders through commercial and residential property tax bases (Alm, Buschman, and Sjoqvist, 2014; Shoag and Veuger, 2018; Tsivanidis and Gechter, 2019) and through support for females and minority entrepreneurship (SBA, 2018). Thus, taken in this light, the proportion of PPP funds tapped by microbusinesses and nonemployers might have induced large welfare gains. Such a finding would provide a counterpoint to prominent arguments for letting existing unemployment insurance nets and creative destruction work in the market in an effort to save funds for the revival of growing enterprises, rather than subsidizing survival of all small businesses (Rajan, 2020). In short, designing small business assistance with a single-minded focus on job creation risks creating zombie main streets and a greater geographic concentration of commerce and wealth (Austin, Glaeser and Summers, 2018).

To make more progress on these welfare tradeoffs is beyond the scope herein. Yet, sound small business policy points to the need to account for the divergent welfare effects of supporting different size small businesses through periods of macro distress. For the same reasons, policy must also consider how the heterogeneities in small business survival capabilities map to the design of specific small business assistance programs. Our contribution is to provide that mapping.

The rest of the paper is organized as follows. In Section 2 we present our framework for small business survival capabilities. We describe our data in Section 3 and provide summary statistics for each of the four data sets that comprise it. Our empirical results are reported in Section 4. Section 5 examines the policy implications of our findings with respect to the design of small business assistance programs. Section 6 reports on whether the PPP and PUI affect medium term survival in Oakland, building off the policy frame. Section 7 concludes.

\section{FRAME}

We lay out a simple frame of the components of firm-level cash flows to fix ideas. We define cash flows $\pi$ as net revenues $(r)$ minus labor costs $(l)$ and committed other costs $(c)$ :

$$
\pi=r-l-c,
$$

where net revenues $(r)$ is revenues minus the inventory costs of goods sold. We consider a negative macro shock $R^{-}$to the economy, which imposes a loss of a unit of net revenue on average for small businesses, but with variance across firms. We are interested in the survival of a firm defined as the maintenance of positive cash flows from the existing cash flow position of the firm following the macro shock, or:

$$
\text { survival }:=\pi+\frac{d \pi}{d R^{-}}>0 \text {. }
$$

Taking the derivative and allowing for labor to scale with revenues or be directly impacted by the shock, we have the survival condition as: 


$$
\underbrace{\left(r+\frac{d \mathrm{r}}{d R^{-}}\right)}_{\text {revenue grit }}-\underbrace{\left(l+\frac{\partial l}{\partial r} \frac{d r}{d R^{-}}+\frac{d l}{d R^{-}}\right)}_{\text {labor flexibility }}-\underbrace{\left(c+\frac{d \mathrm{c}}{d R^{-}}\right)}_{\text {committed costs }}>0 .
$$

Survival is a function, first, of the ability of firms to exhibit revenue resiliency, preserving as much of ex ante revenue as possible. Next, survival is a function of labor cost flexibility, which incorporates how elastic a firm's labor cost is to revenue as well as direct labor effects from the macro shock. Finally, survival is a function of the size of the committed costs and the ability to restructure costs following the shock $R^{-}$.

In our empirical analysis, we assume that the ability to deploy these three survival tactics are capabilities of firms in the sense that firms will optimally do whatever they can to adjust to the macro shock. We estimate these survival capabilities with the lens of looking at how they vary by firm size, focusing on our three categories of nonemployers, microbusinesses, and enterprises, all within industry sector.

We then map the results to inferences concerning policies aimed at supporting small businesses during periods of macro distress. In particular, we consider three sets of program features in terms of how they relate to our frame:

Subsidized Working Capital Loans. Programs such as Economic Injury Disaster Loans (EIDL) offered through the SBA provide subsidized loans to business struggling with natural disasters. These programs impose conditions on recipients to ensure that loan proceeds are used to support working capital in rebuilding revenues. Recipients of EIDLs, for instance, are prohibited from using loan proceeds to refinance long-term debt or expand operations. As summarized by the SBA, EIDLs are for entities who are "ready to 'restart' their operations once circumstances allow" (SBA 2020). These subsidized working capital loans should therefore be most useful for those firms that have revenue resiliency among their survival capabilities.

Labor Costs Grants and Subsidies. Programs such as the Paycheck Protection Program and Pandemic Unemployment Insurance (as used by nonemployers as income-substitution) provide a subsidy to labor costs, conditional on labor remaining in place. Payroll tax holidays (e.g., on the employer match for Social Security payroll taxes, as was done by President Carter in Jobs Tax Credit in the Tax Reduction and Simplification Act of 1977 and more recently in the CARES Act) would also subsidize continuing employment. These policies will be effective when most workers are either the owner or core function employees, but may be less efficient and attractive for small businesses endowed with high labor flexibility that they use to survive business cycle downturns.

Lease or Debt Payment Restructuring Subsidies. Governments might choose to implement policies aimed to reduce the committed cost burdens on small businesses akin to the Home Affordable 
Modification Program (HAMP) applied to households and lenders during the Great Recession whereby the government subsidizes the lender (or leaseholder) to restructure the obligation. In the context of small businesses, these programs may take the form of providing government grants that can be used to offset commercial lease costs. Facilitating small businesses bankruptcy reorganizations would also have the effect of providing small businesses with leverage to restructure large committed costs. We provide examples of both forms of these programs in Section 5. Either form of program will be especially relevant for small businesses whose survival will depend on their ability to restructure large committed costs incurred prior to the macro shock.

\section{DATA AND SUMMARY STATISTICS}

A primary challenge confronting research about small businesses concerns the unavailability of firm performance data. We address this challenge through a multi-step data collection process that exploits our ability to collect real-time data as small businesses began to experience the impact of the COVID-19 economic shutdown. These real-time data come from the following four sources.

\section{A. City of Oakland Small Business Survey}

In early March 2020, well before Alameda County imposed its shelter-in-place order, the City of Oakland constructed a survey to elicit information from its small business community about resiliency during the COVID-19 pandemic. The City's survey went live three days prior to the March $16^{\text {th }}$ announcement of the County's shelter-in-place. Our core analyses focus on responses submitted between March 13, 2020 through April 1, 2020. Our sample starts with 1,088 surveys. After filtering out 37 businesses with more than 50 employees, 19 purely online businesses, and 18 nonprofits, we have a sample of 1,014 firms. Based on census data, we estimate that the survey captured approximately 11-15\% percent of the city's businesses. ${ }^{6}$

Table 1 reports the summary statistics from the City of Oakland survey. Panel A reports the sample statistics regarding employment, covering the following variables:

Nonemployer : = An indicator for the firm reporting no employees.

Microbusiness: $=$ An indicator for the firm reporting 1-5 employees.

Enterprise : = An indicator for the firm reporting 6-50 employees.

\footnotetext{
${ }^{6}$ According to the 2017 County Business Patterns from the U.S. Census Bureau, there were nearly 14,000 private and government establishments in Oakland's zip codes. Using this number directly would imply that our sample captures $7.8 \%$ of Oakland's businesses, but this is too conservative as the census total (i) includes businesses with up to 500 employees (and our survey is for small businesses), (ii) assumes that small businesses only have one establishment, (iii) includes non-revenue generating registered businesses, and (iv) includes schools, government offices, and other non-business organizations.
} 
Employees : = Full-time and part-time employees prior to March, 2020.

Percentage Change Job Losses : = Full-time and part-time positions lost early in the shutdown, relative to reported pre-crisis full- and part-time positions.

A quarter of the sample of Oakland small business are nonemployers, 43\% are microbusinesses, and 32\% are enterprises. The mean (median) employee count is 6.5 (2) for all small businesses and 8.7 (4) for businesses excluding the nonemployers. Of these jobs, $17.7 \%$ were already lost on average in the first weeks of the shelter-in-place.

Panel B reports statistics on reported revenues.

Declining : = Whether or not the business was ex ante declining, defined as year-over-year declining in gross receipts as of February 2020.

Percentage Change Receipts : = Reported percentage change year-over-year gross receipts as of March 2020 based on a firm's selection of one of six ranges.

Approximately half of all respondents indicated a decline in year-over-year (YoY) revenue as of February 2020, the month prior to the shelter-in-place order. We use this indicator variable below as our proxy for indicating whether a firm's financial distress pre-dated the U.S. COVID-19 crisis. The fact that half of small businesses might have negative growth is consistent with the results in Decker et al. (2014) and Hurst and Pugsley (2011) concerning the non-growth nature of most small businesses. Also in Panel B, we report the distribution of gross receipts YoY as of March 2020. By early March, businesses were severely impacted first by self-imposed staying out of public spaces and then, on March 16, by the county ordinance. This shows up in the distribution in Panel B, where 69\% of respondents report a year-over-year decline of over $40 \%$ for March.

In Panel C, we report the distribution to the response on closure risk.

Closure Risk := Whether the small business owner responded that s/he was "very concerned" about the risk of closure, "somewhat concerned" or "not concerned".

Overall, 73\% of respondents were very concerned about closure and only 4\%, not concerned.

As part of this survey, the City of Oakland subsequently conducted a follow-up survey completed by nearly 300 of the small businesses. We examine this follow-up survey in Section 5.

\section{B. Hand Collected Information on Small Business Operations}

We obtain additional operating data on these businesses from manual firm-by-firm internet searches conducted between April 24, 2020 and May 3, 2020 — the day on which Alameda County permitted certain outdoor businesses to recommence operations on a limited basis. We began these manual searches on Google Maps. Companies, particularly street-facing companies, had a large incentive to keep their Google Maps status updated, and businesses informed us that Google aggressively solicited each establishment for 
this information. We additionally searched for the company website and other internet sources of information to determine the operating status for each survey company.

For each business, we coded the following variables.

- Industry := Narrowly-defined industry.

- Main Street : = An indicator for a business being on a street-facing location (on “main street”).

- Essential : = Whether the business constitutes an “essential business” under Alameda County’s shelter-in-place order (e.g., grocery stories, lumber and repair, pharmacies, and physician offices).

Panel A of Table 2 breaks down the distribution of industries and provides detailed examples of the type of businesses in each category. Panel B reports that two-thirds of the sample are "main street" facing, and a third provide their goods and services at a home or at an office that is not "main street" facing. We coded eleven percent of respondents to be deemed essential businesses under the shelter-in-place rules.

Panel C of Table 2 reports the status of the ongoing concern.

- Status : = The hand-coded operating status of the business at the time of the search, coded among: Permanently Closed (or Lacking Ongoing Concern Signal), Temporarily Closed, Trying, and Open.

A firm classified as Trying (21\%) indicates a firm that was not permitted to operate under the shelter-inplace order but nevertheless conducted operations under alternative arrangements or reduced revenue models. For example, this class of businesses might include a restaurant that operated on a limited takeout/delivery basis or a yoga studio that operated remotely through video conferencing. The Temporarily Closed status, which was actively pursued by Google Maps to provide its customers with accurate availability of businesses, accounted for approximately 26\% of the sample. We overrode Google Map's Temporarily Closed to be Trying if the business website indicated that it was operating in some form to generate revenues; most Trying businesses were marked Temporarily Closed by Google, except for restaurants, which were market "take-out only” or “delivery only” (or both). The Permanently Closed (or Lacking Ongoing Concern Signal) businesses (19\%) were a combination of those businesses that were explicitly marked as permanently closed by Google Maps as well as those businesses which showed no sign of any ongoing business on their webpages and did not indicate that they were temporarily closed.

In Figure 1, we plot the status by industry in pie charts, to underscore the economic challenge to survey respondents posed by the COVID-19 pandemic. Temporary closures were especially high within the salons, retail, fitness/salon/wellness sector, and construction sectors. Only in the medical, professional services and personal services was the Open category the dominant classification. In contrast, the Trying classification was prevalent among restaurants, fitness, and retail. 


\section{HomeBase}

Our third set of data comes from HomeBase, a workplace scheduling and payroll management company that caters primarily to small businesses. ${ }^{7}$ The HomeBase data includes anonymized data for an establishment's weekly employee headcount and, for some firms, reported weekly wages paid to some or all employees. We filter the HomeBase data to all business establishments that have a U.S. zip code and a disclosed industry and that have 50 or fewer average employees between January 1, 2020 and February 15, 2020.

In Panel A of Table 3 we report summary statistics for this sample of HomeBase establishments. Our primary interest is in the following two weekly measures:

- Headcount : = Weekly full- and part-time employees (regardless of whether wages are disclosed) per location.

- Payroll : = Weekly wages paid to employees for whom wages are disclosed.

Column 1 - 4 indicate that HomeBase firms within our sample had a mean (median) employee headcount of 7.6 (5.5) during the period January 1, 2020 and February 15, 2020. Not surprisingly, employee headcount varied by industry, ranging from a low of 4.34 (3) among establishments in the Beauty \& Personal Care industry to a high of 9.21 (7.3) within the Food \& Drink industry. In Columns 5 - 8 we similarly present summary data concerning total weekly wages paid for those establishments that reported the weekly wages paid to one or more employees over the same period. Among these firms, mean (median) pre-crisis wages paid per week were roughly $\$ 2,400$ (\$1,500). Across industries, Beauty \& Personal Care establishments were the lowest paying within the sample, while Transportation establishments paid the most, presumably reflecting the higher hourly wage rates paid by these latter firms.

In Figure 2 we plot the distribution of our sample of HomeBase establishments by state. California, Florida and Texas claim roughly 16\%, 10, and 9\% of establishments, respectively.

\section{SafeGraph Foot Traffic Data}

Our final dataset is data on foot traffic in establishments from SafeGraph for January 1, 2020 to April 30, 2020. SafeGraph covers mobile locations for over thirty million individuals using cellphone tracking information that these individuals have consented to sharing pursuant to one or more applications installed on their mobile devices. SafeGraph overlays this tracking data to 5 million U.S. establishments or "points of interest” (POI) based on the actual location and shape of the POI (i.e., its polygon) rather than its address, thus allowing SafeGraph to identify each instance when an individual visits a POI.

\footnotetext{
${ }^{7}$ These data have been made available by HomeBase for researchers examining the labor market impact of COVID19 and have been a primary source of data for examining overall employment trends within the small business sector during the COVID-19 economic crisis (see, e.g., Bartik, et al.).
} 
Figure 3 maps the mean number of devices during this period for all counties in the continental U.S. and within California. SafeGraph tracked over one thousand devices in over half of all counties. In Alameda county, the focus of our study, SafeGraph tracked over 50,000 devices, allowing us to use these data as a proxy for the revenue of small businesses, particularly for "main street" businesses whose cash flow is likely to depend on foot traffic.

We cannot use the data to infer dollars of revenue per se, as different store types have different conversion rates of customers to revenues. Yet, we can use foot traffic to infer the revenue shock, using firm fixed effects, following the approach of investigative journalists and policymakers examining the impact of the COVID-19 crisis on consumers. ${ }^{8}$ Figure 4 illustrates the feasibility of this approach, focusing on select industries within Alameda-Restaurants, Electronics and Appliance Stores, Fitness/Sports Centers, and Grocery Stores. We standardize visits by observed daily devices and calculate the moving average over the preceding seven-day period. Plotted is the moving average over time relative to that for January 8, 2020. All businesses suffered a significant drop in foot traffic following the shelter in place order, which is represented by the dashed vertical line on March 16. The primary exception relates to the surge in grocery store foot traffic in the days immediately following the announcement of the order as residents flooded grocery stores.

We match the Oakland small businesses survey respondents to the Safe Graph POI dataset by business name, enabling us to assess directly the extent to which a business' foot traffic was impacted by Alameda County's shut-down in economic activity. (Service companies without storefronts - construction, consulting, realty, etc. - are often not covered in SafeGraph, nor would foot traffic represent a meaningful concept of commerce for these businesses.) These foot traffic data span from January 1, 2020 to April 30, 2020; however, we drop the period of closing down in late March (March 16 to March 31), to ensure that our foot traffic data reflects commercial activity as opposed to visits related to the closing down of a business. We find exact matches for 268 small businesses, mostly for main street-facing businesses.

We report in Panel B of Table 3 summary statistics for our primary metric of interest, average daily foot traffic for each location by coded industry. As in Figure 4, the reported figures account for variation in the number of observed devices by scaling the daily visits to an observed POI by the number of devices observed by SafeGraph in Alameda County per 100,000 residents. Data represent the overall mean number of standardized daily visits between January 1, 2020 and March 15, 2020. Across industries, this standardized measure of daily visits ranged from a mean (median) of 0.85 (0.74) for medical offices to 7.55 (5.37) for restaurants.

\footnotetext{
${ }^{8}$ See, e.g., Megan Cerullo, Phone data show consumers avoiding stores, restaurants as COVID surges, CBS News, July 2, 2020, available at https://www.cbsnews.com/news/cell-phone-data-show-consumers-avoiding-stores-ascovid-19-cases-surge/.
} 


\section{RESUlTS}

We test whether the facets of small business survival - revenue resiliency, labor flexibility, and committed cost - vary by firm size in their reaction to the economic crisis caused by the COVID-19 sheltersin-place. In our estimations, we consider the role of ex ante (pre-crisis) firm size using two independent variables - the natural log of workers (where "workers" equals employees +1 , the owner) and an indicator for a nonemployer firm. The nonemployer indicator is used to pick up any unique attributes of nonemployers that a continuous variable might miss. We then group predictions into three size buckets (following our bakery, taqueria, and pizza restaurant examples) to depict patterns of the predicted effects by size type, always absorbing industry or firm fixed effects, to depict patterns orthogonal to these systematic influences.

\section{A. Revenue Resilience Results}

\section{A.1. Oakland Survey Revenue Resilience Results}

Table 4 presents results from two revenue resiliency analyses. In column 1-4, we report estimates within the Oakland survey data as follows, denoting the small business by $i$ :

$$
\begin{gathered}
\log (\% \triangle \text { Receipts Decline March })_{i}=\beta_{0}+\beta_{1} \text { LogWorkers }_{i}^{\text {Pre }}+\beta_{2} \text { Nonemployer }_{i} \\
+\beta_{3} \log (\% \triangle \text { Receipts Decline February })_{i}+\mu^{\text {mainstreet }}+\mu^{\text {essential }} \\
+\mu_{\text {industry }}+\varepsilon_{i}
\end{gathered}
$$

The dependent variable is the log of 1 plus the percentage change decline in YoY gross receipts for March 2020. ${ }^{9}$ The dependent variable is increasing in the decline in revenues. All columns include the variable $\% \Delta$ Receipts Decline February, which is the same variable as the dependent variable except YoY revenue is reported as of February, 2020, thus allowing us to parse-out the pre-crisis situation of the firm and focus on the effect of the pandemic stress. In addition, all columns include indicators for the business being located on main street ( $\mu^{\text {mainstreet }}$ ) and whether or not the business is essential $\left(\mu^{\text {essential }}\right)$. All columns have our main independent variable, log of workers, and Columns 2 and 4 also include the nonemployer indicator to allow for any unique attributes of this type of business. Columns 3 and 4 include industry fixed effects $\left(\mu_{\text {industry }}\right)$.

Turning to the results, we first look to the conditioning variable Log Receipts Decline February. The March decline in receipts has a very tightly-estimated elasticity of 0.220 to the February decline in receipts. This elasticity is well below 1, reflecting the large change in the setting in March. Nevertheless, this variable

\footnotetext{
${ }^{9}$ Note that the gross receipt decline variables are reported in the survey in buckets, as depicted in Table 1, not as a continuous variable. We make a continuous variable, taking the midpoint of the bucket as the value. An ordinal logit estimation fits a similar pattern as what we report, but with more noise.
} 
is the most important in terms of partial R-squared in the estimation, even much more so than the industry effects, which are surprisingly insignificant with other variables included. The main street and essential variables (which sometimes compete with the industry effect for power) are also weak in explanatory power. In short, it appears that the shelter-in-place affected businesses across the board, hitting those already in decline $22 \%$ more, but with much idiosyncratic impact.

Our main variables of interest, workers and nonemployers, are also statistically important. We find a gross receipts elasticity of 0.027 to the number of workers in the firm, once we allow nonemployer firms to exhibit their own pattern (columns 2 and 4). Larger firms exhibit a greater percentage revenue decline.

In Figure 5, panel A, we plot the marginal effect of log workers and nonemployer status on percentage decline in gross receipts for March at the mean value of all other variables (using the specification shown in column 4.) We plot this marginal effect averaged into our three small business types - nonemployers, microbusiness, and enterprises. The figure shows that microbusinesses face a YoY revenue percentage decline for March of -0.408 , a large number, but better than enterprises, who face a revenue decline of 0.476 as a percent of the prior year's gross receipts. Interpreting the result in the context of our setup, microbusinesses seem to be endowed with the ability to ward off $14 \%$ of the shock relative to enterprises. In the context of real-world events captured by our hypothetical businesses, the taqueria-because it is small—is able to more nimbly keep a larger proportion of pre-crisis revenues.

\section{A.2. SafeGraph Revenue Resilience Results}

In the last two columns of Table 4, we instead turn to the SafeGraph data of foot traffic as a revenue proxy, again focusing on Oakland, where we know employee counts. These data are a panel, allowing us to estimate a model to absorb firm heterogeneity and time, akin to a difference in differences model, but

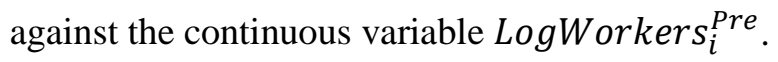

$$
\begin{gathered}
\text { LogFootTraffic }_{i t}=\beta_{0} * \text { Post }_{t}+\beta_{1} \text { LogWorkers }_{i}^{\text {Pre }} \text { Post }_{t}+\beta_{2} \text { Nonemployer }_{i} \text { Post }_{t} \\
+\gamma_{i}+\delta_{t}+\varepsilon_{i t} .
\end{gathered}
$$

Variables $\gamma_{i}$ and $\delta_{t}$ denote firm and day fixed effects, respectively. Post $t_{t}$ represents March 30 - April 30, 2020.

As shown in columns 5-6 of Table 4, foot traffic fell dramatically across firms during the Post period, as would be expected. We find that this decline is especially pronounced for nonemployers and larger businesses. We again turn to a graphical representation to put our economic magnitudes into perspective.

Panel B of Figure 5 plots the predicted log of foot traffic over time by small business type, after removing firm fixed effects. Note that for the pre-crisis period, the lines pick up a single time-varying pattern because LogWorkers is static by firm (and thus absorbed by the fixed effect) until March 30, when the interaction with Post estimates elasticities by firm size. As the picture illustrates, all types of businesses 
incurred a tremendous reduction in foot traffic after the shelter-in-place order; the average decline is $71.9 \%$. However, whereas enterprises and nonemployers face $73.8 \%$ and $73.1 \%$ percentage declines in their foot traffic, microbusinesses have somewhat higher revenue resiliency, facing only a $68.4 \%$ decline. This is not to say that a $68 \%$ decline in revenues is benign, but microbusinesses seem to be able to ward off $8 \%$ of the shock relative to the other types of business, on the order (14\% better) of our finding in the Oakland survey.

\section{B. Labor Flexibility Results}

In the forthcoming labor flexibility and committed costs estimations, we need to control for revenue losses, to avoid double-counting any effects we estimate in Table 4 by firm size. Thus, we create a revenue loss index variable, defined as the average of a standardized version of the percentage decline in revenue for March from the Oakland survey and a standardized version of the percentage change in foot traffic after the shelter in place (defined to be April) relative to the pre-period foot traffic of January 13 - February 18, 2020. Because some observations lack one or the other variable, we allow solo contributions of these standardized variables.

\section{B.1. Oakland Survey Labor Flexibility Results}

We now test whether the labor flexibility facet of small business survival varies by firm size in its reaction to the economic crisis caused by the pandemic. Table 5 presents estimates of labor flexibility in the Oakland survey in the following specification:

$$
\begin{aligned}
& \text { FractionalLogit }\left(\% \Delta \text { Decline Workers } \text { W }_{i}\right)=\beta_{1} \text { LogWorkers }_{i}^{\text {Pre }} \\
& +\beta_{2} \text { RevLossIndex }_{i}+\beta_{3} \text { LogWorkers }_{i}^{\text {Pre }} \text { RevLossIndex } \\
& \\
& \quad+\mu^{\text {essential }}+\mu_{\text {industry }}+\varepsilon_{i} .
\end{aligned}
$$

The dependent variable is a percentage change decline of workers (full-time in columns 1-3 and part-time in columns 4-6). The main independent variable is $\operatorname{LogWorkers}_{i}^{\text {Pre }}$. Because the percentage change decline distribution ranges from 0 to 1 , we estimate a fractional logit for efficiency. As before, we control for the main street and essential business effects and absorb industry effects. We include the revenue loss index to control for the effects documented in Table 4. We also interact the revenue loss index with $\operatorname{LogWorkers}_{i}^{\text {Pre }}$ in some specifications to test whether firm size alters the relationship between labor flexibility and revenues. We focus our analysis on microbusinesses and small enterprises, since nonemployers have no employees.

As Table 5 reports, we find that layoffs of full-time workers (columns 1-3) exhibit an elasticity to firm size of 0.127 , controlling for industry effects (column 2), and layoffs of part-time workers (columns 4-6) exhibit an elasticity 0.172 (column 5) to firm size with these controls. A second result in Table 5 is that although the relationship between revenue losses and labor layoffs is high, as one would expect, the 
interaction of revenue loss and pre-crisis level of workers does not add to the explanatory power. Thus, labor flexibility does not appear to be mediated through differentials in revenue losses among enterprises relative to microbusinesses.

As before, we turn to a figure to depict the economic meaning of our results. Figure 6, panel A plots the relationship between ex ante size of the firm and the marginal effect of the $\operatorname{LogWorkers}_{i}^{\text {Pre }}$ on layoffs, taking all other variables at the mean value. For full-time workers, enterprises on average laid off 38.1 percent of workers, whereas microbusinesses only laid off 17.7 percent. For part-time workers, enterprises laid off 49.6 percent of workers and microbusinesses only 23.8 percent. Recalling that the ability to lay off employees to downsize costs can represent a positive aspect for survival, this result implies that microbusinesses face a much larger risk of not surviving on this metric. In particular, microbusinesses exhibit half (47.6\%) the labor flexibility of enterprises.

\section{B.2. Homebase Labor Flexibility Results}

Parallel with the Oakland survey data, we now look at the employment and payroll data from Homebase. As before, we combine with a revenue loss dataset, in this case, with foot traffic data from SafeGraph. Establishments in the HomeBase data are anonymized; therefore, we cannot match firm-tofirm. Instead, we match each HomeBase establishment based on its industry and zip code to SafeGraph foot traffic data and use the mean weekly foot traffic for SafeGraph POIs within the same industry-zip as a proxy for revenues. For our measure of firm size, we use a HomeBase establishment's average headcount data between January 1, 2020 to February 15, 2020. We focus our labor flexibility estimations excluding nonemployers.

Denoting index $j$ to indicate industry-zip code of firm $i$, we estimate parameters from the following:

$$
\begin{aligned}
& \text { LogLaborCost }_{i t}=\beta_{0} \text { Post }_{t} \\
& +\beta_{1} \text { LogFootTraffic }_{j t}+\beta_{2} \text { LogFootTraffic }_{j t} \text { Post }_{t} \\
& +\beta_{3} \text { LogWorkers }_{i}^{\text {Pre }} \text { Post }_{t}+\beta_{4} \text { LogWorkers }_{i}^{\text {Pre }} \text { LogFootTraffic }_{j t} \\
& +\beta_{5} \text { LogWorkers }_{i}^{\text {Pre }} \text { LogFootTraffic }_{j t} \text { Post }_{t}+\gamma_{i}+\delta_{t}+\varepsilon_{i t} \text {, }
\end{aligned}
$$

where the labor cost dependent variable is either workers or payroll. Variables $\gamma_{i}$ and $\delta_{t}$ denote firm and

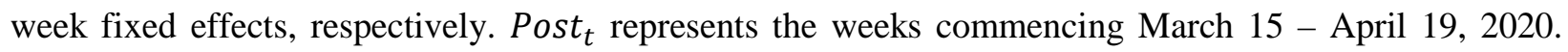
Results are presented in Table 6, first for the area surrounding Oakland (the 94XXX zip codes, including the East Bay, North Bay and San Francisco) in columns 1-3 and then nationally (in columns 4-9). The results are not sensitive to defining the Oakland area more narrowly, and we cluster standard errors at the firm level to balance the panel's influence. Columns 4-9 widen the sample nationally, and columns 7-9 consider payroll rather than worker counts, but we are more cautious in magnitude interpretation with 
regards to payroll, as the sample size declines materially after the crisis relative to the employment numbers, suggesting a selection problem.

The specification is, as in the foot traffic estimation, akin to a difference-in-differences, except that we are interested in the post effect surrounding a continuous variable LogWorkers $_{i}^{\text {Pre }}$. Because we can implement identification absorbing firm and time effects, our specifications will produce estimates with Rsquares of at least 0.83 .

After the pandemic began, firms experience a large shock to employment, with a post decline of -0.42 percentage change in Oakland (column 2) and -0.50 percent decline nationally (column 5). This shock is not accompanied by a shock to the elasticity between revenue and labor: in columns 2 and 5 , the coefficients on LogFootTraffic ${ }_{j t}$ Post $_{t}$ are not significant. This suggests that on average, employees scale with revenues. This interpretation holds for the results in column 8 for wages.

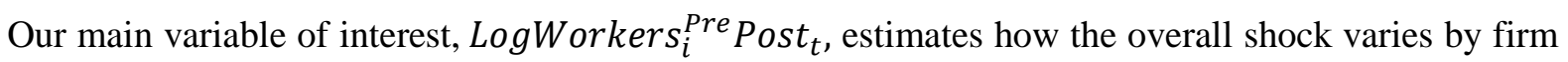
size. We find the small businesses with more pre-crisis workers experience larger decreases in workers and payroll, with a post-period shock to the elasticity of labor to the firm size of approximately -0.25 to -0.30 (columns 2,5, and 8).

In columns 3, 6 and 9, we add the three-way interaction of LogWorkers $_{i}^{\text {Pre }}$ LogFootTraffic $_{j t}$ Post $_{t}$ to examine whether these effects are coming from shocks to the elasticity of labor to revenues varying by firm size or if the effect is just labor utilization adjustments by firm size that are independent of revenue resiliency. To make such an assessment, we first look at how the pre-crisis elasticity of labor costs to revenue vary by firm size. We find that the revenue-to-cost relationship is highly dependent on firm size, noting that the inclusion in columns 3, 6 and 9 of LogWorkers $_{i}^{\text {Pre }}$ LogFootTraffic $_{j t}$ erodes the relationship between labor costs and LogFootTraffic $j$ alone. The interpretation, consistent with the role of a core employee in our taqueria versus pizza restaurant example, is that larger firms generally exhibit more labor scaling with revenue. Notably, however, the pandemic shock does not alter the relationship very much: the triple interaction of post with firm size and revenues (foot traffic) is not significant in columns 3 and 9. It is positive and significant in column 6, the national sample of workers, suggesting that if anything, the pandemic shock makes the elasticity of labor to the revenue macro shock even stronger for larger enterprises. This result, however, does not materially affect the statistical or economic significance of the coefficient on $\operatorname{LogWorkers}_{i}^{\text {Pre }}$ Post $_{t}$. This leads the conclusion that the firm size effect on employment is primarily the direct effect of the shock on labor, not one working through a change in the elasticity of labor cost to revenues that varies by size.

We turn to graphs to depict the economic magnitude. In particular, we use the estimations in columns 3, 6 and 9 to depict changes in worker counts across microbusiness and enterprises relative to the first week 
of our panel. Figure 6 Panel B presents the column 3 marginal effects for the Oakland region. The parallel implications from Figure B, next to Panel A, is evident. The fall in employment is sharp and drastic. Yet, microbusinesses experience a noticeably lower decline in workers relative to pre-crisis levels, indicating a lower flexibility in adjustments. When we translate these predictions to business type, we find that workers decline by 50.1 percent for enterprises, but only by 26.7 percent for microbusinesses in Oakland. These number are very close to our survey estimates in Panel A of Figure 6 (among part-time employees, 49.6 percent decline for enterprises and 23.8 percent decline for microbusinesses).

Figure 6, panel C depicts the national results, with a very similar relationship as Panel B. Relative to the Oakland results, the decline is a bit muted on average; however, the difference between microbusinesses and enterprises remains evident. Whereas microbusinesses respond to the pandemic with a reduction in workers by 18.6 percent, enterprises on average reduce the workforce by 44.9 percent.

Finally, Panel D plots the predicted time pattern of payrolls for national establishments from the column 9 estimation, again removing firm effects. The payroll data are, as mentioned, less reliable in that there appears to be selection in reporting in the later month. Nevertheless, we find that the percentage decline is a large 47.2 percent on average, but the differential by firm size is a bit tighter. Whereas enterprises are able to cut back payrolls 55.1 percent, microbusinesses only are able to trim these costs by two-thirds as much, 37.1 percent. Thus, our punchline labor flexibility result is that facing a large macro shock, microbusinesses have only one-half to two-thirds as much labor flexibility as enterprises. This finding has a direct implication for the PPP design, offering nuance to the assessment of Chetty et al. (2020) who find the PPP failed to spur employment across all small businesses. We return to this topic in section 5.

\section{Committed Costs - Closure Risk}

Finally, we turn to committed costs. We cannot observe committed costs directly. Instead, we take guidance from our framework which indicates that once we have removed the heterogeneities of revenue resiliency and labor flexibility, the residual must contain the role of committed costs in survival. We therefore use residual closure risk as a proxy for committed costs. In particular, within the Oakland survey, we estimate:

$$
\begin{aligned}
& \text { Ordered Logit ( } \\
& +\beta_{3} \% \triangle \text { Decline Workers }+\sum_{k=1}^{K} \xi_{k} \text { InterimOucome }_{i k}+\mu^{\text {declining }} \\
& +\mu^{\text {mainstreet }}+\mu_{\text {industry }}+\varepsilon_{i} .
\end{aligned}
$$

Closure Risk Concern $i$ is the ordered answer to the Oakland survey question of how concerned a business owner is about closure. We include the revenue loss index and percentage change decline in workers to absorb those firm-level determinants of closure. We also include whether the firm was declining in the 
February YoY gross receipts. Finally, and perhaps most importantly, we include our interim outcome measures $\sum_{k=1}^{K} \xi_{k}$ InterimOucome $_{i k}$ that we hand collected. The idea is that we want to fully absorb business-level heterogeneities unrelated to the longer-term effects of committed (fixed) costs. Thus our collecting the late-April (interim) outcome of the firm allows us to remove any additional variation related to variable costs that we do not observe perfectly in the survey data. We also include the main street and industry variables for this purpose.

Once we have removed all of these causes of closure risk, we argue that any residual variation picked up by $\beta_{1} \operatorname{LogWorker}_{i}^{\text {Pre }}$ reflects the fact that committed costs vary (if any) by the size of the small business.

Results are presented in Table 7. We find that committed costs (the residual component of closure risk unaccounted for by the covariates) is increasing in $\operatorname{LogWorkers}_{i}^{\text {Pre }}$, across the columns. The exception is column 2, where the inclusion of the nonemployer dummy causes a horse-race for the upward trend. The covariates of revenue loss and labor losses also strongly predict closure risk. The other variables included to control for unobservable revenues changes or variable costs - declining and the outcome measures - are also important, in signs expected, in explaining expected closure. We include an industry fixed effects model (column 3) as well as a random effects model (column 4). Fixed effects for ordered logit are of questionable consistency; thus the random effects may be preferred as a more reliable estimator.

In an ordered logit, the coefficients are log odds ratios. We therefore exponentiate these coefficients in the line beneath the standard error to allow for an odds ratio interpretation of the effect of LogWorkers ${ }_{i}^{\text {Pre }}$. Across respondents, a $10 \%$ increase in workers was associated with a $2 \%$ increase in the odds of being at a level higher in closure risk.

As previously, we present these estimated effects graphically to highlight the marginal effect by the small business type. Figure 7 plots the marginal effect of worker size from column (4), taking all the other variables at the mean level. The picture depicts, first, that the closure risk overall is incredibly high, as we showed in the summary statistics. A clear relationship exists between firm size and closure risk beyond the effect of the covariates. In particular, in explaining residual closure risk, enterprises have an $11 \%$ greater outlook of "very concerned" compared to microbusinesses and a 22\% greater outlook of "very concerned" relative to nonemployers. We interpret these results as indicating that, relative to microbusinesses and nonemployers, enterprises face a respective $11 \%$ and $22 \%$ higher closure risk due to committed costs. We, of course, need the caveat that in drawing this inference, we are relying on a proxy for fixed costs, as guided by our framework in Section 2. Nonetheless, the result is quite intuitive; a larger establishment faces a higher role of capital (and thus debt) and a higher role of property costs in its design. What is important is that the finding controls for the importance of revenue and labor, and interim variable costs we can measure with interim outcomes. Thus, we think our interpretation of committed costs is quite plausible. 


\section{Policy Program Features}

With survival capabilities results in hand, we turn to examining how these survival capabilities are, or are not, compatible with small business assistance programs across the classification of businesses we study. We use the following graphic to direct the discussion, where the top three rows summarize our findings regarding the primary survival capabilities, and the bottom rows examine how these capabilities relate to policy options.

\begin{tabular}{|c|c|c|c|}
\hline & Nonemployer & Microbusiness & Enterprise \\
\hline Survival Capability: & \multicolumn{3}{|c|}{ Feasibility of Strategy } \\
\hline Exhibit Revenue Resiliency & Moderate & High & Moderate \\
\hline Exercise Labor Costs Flexibility & Low & Low & High \\
\hline \multirow[t]{2}{*}{ Rely on Low/Flexible Committed Costs } & High & High & Low \\
\hline & Nonemployer & Microbusiness & Enterprise \\
\hline Small Business Assistance Program: & \multicolumn{3}{|c|}{ Compatibility of Program } \\
\hline Subsidized Working Capital Loans & X-to- $\checkmark$ & $\checkmark$ & X-to- $\checkmark$ \\
\hline Labor Costs Grants and Subsidies & $\checkmark$ & $\checkmark$ & $\mathrm{X}$ \\
\hline Lease or Debt Payment Restructuring Subsidies & $\mathrm{X}$ & $\mathrm{X}$ & $\checkmark$ \\
\hline
\end{tabular}

We start with microbusinesses. Microbusinesses have low labor flexibility, since their employees must be jack-of-all-trades. We found that their survival depends on maintaining revenues to cover these inflexible labor costs, as well as having relatively lower residual committed costs. Thus, working capital loan programs that focus on supporting revenue resiliency through financing activities like restocking inventories and conducting repairs are highly compatible with microbusinesses' survival capabilities that depend on maintaining pre-crisis revenues. Recall, for instance, our hypothetical taqueria faced with a local economic crisis. Lacking the ability to lay off staff, the business owner was faced with the stark choice of demonstrating revenue resiliency or shutting down. Assistance to support these revenue strategies following an adverse economic shock is reflected in conventional Economic Injury Disaster Loans (EIDL) offered through the SBA. According to the SBA, "[t]he sole purpose of an [EIDL] is to help a small business meet its working capital requirements during the disaster-affected period until normal operations resume.” To this end, loans proceeds are calculated as a function of pre-crisis gross margins, and recipients are prohibited from using proceeds to refinance loan term debt or expand operations. Instead, loan proceeds are intended to aid small businesses in rebuilding revenues to pre-crisis levels. Programs, such as the New York Forward Fund as well as the Main Street Lending Program, are similarly designed to provide working capital to businesses seeking to rebuild revenues in connection with the COVID-19 pandemic. 
Likewise, PPP-like programs are also well-suited for microbusinesses. The taqueria cannot lay off the few jack-of-all-trades employees and still remain open, thus making microbusinesses an ideal target for the PPP, as well as for several other programs created by the CARES Act. For instance, the CARES Act provides for a refundable payroll tax credit for employers to offset the cost of maintaining employees. The role of the PPP (and similar programs) for microbusinesses contrasts our findings with those of Chetty et al. (2020), who evaluate the efficacy of the PPP in stimulating employment. Using a national sample of small businesses, these authors find that the PPP had no meaningful impact on employment rates, leading these authors to conclude that "that providing liquidity itself may be inadequate to restore employment at small businesses." Critically, however, their sample of firms focused on enterprises; the smallest strata of firms they considered had an average of 45 employees. Yet, as we have shown, it was precisely these larger employer firms that are the most likely to rely on their labor flexibility to weather the COVID-19 pandemic — a survival tactic that is at odds with the PPP's labor subsidy.

Turning to nonemployers, we found that these businesses exhibit neither revenue resiliency nor labor cost flexibility. Instead their survival relies on low committed costs (22\% lower than enterprises). These results are complemented with prior research showing nonemployers' personal flexibility in accepting nonpecuniary utility rather than full income in down times (e.g., Moskowitz and Vissing-Jorgensen, 2002). Because this personal utility nevertheless consumes personal wealth (which has limits), policies aimed at preserving incomes for self-employed individuals are well-suited to support nonemployer owners through an economic downturn. Thus, labor cost supporting programs aimed at these individuals, such as the creation of Pandemic Unemployment Insurance under the CARES Act, can likewise be viewed as compatible with nonemployer survival capabilities. In contrast to microbusinesses, working capital loans may only be somewhat compatible with nonemployers' survival capabilities in the short term since revenues are not resilient. This contrasts with the medium term, where working capital loan programs can support nonemployers' reduced revenue models as the economy recovers, especially since these businesses have lower committed costs.

Finally, for enterprises, we found that these businesses exhibit only moderate revenue resiliency, but their $50 \%$ greater labor flexibility, compared to microbusinesses, allows enterprise to decrease costs immediately for survival. However, enterprises also possess the greatest residual exposure to committed costs, which jeopardize their short-term survival despite their greater labor flexibility. For businesses that reduce employee headcount as a means to survive a macro shock, labor cost grants and subsidies are not likely to be the most effective use of government support, consistent with Granja et al. (2020) and Chetty et al. (2020)'s findings regarding the low employment rate by firms (all enterprises) receiving a PPP loan. Likewise, similar to our assessment of nonemployers' survival capabilities, working capital loans may not be effective in supporting enterprises' survival capabilities in the short term since revenues are not resilient, 
but might support their reduced revenue models as the economy recovers. For enterprises, however, this support is overshadowed by the risk of failure caused by committed costs.

Short term survival for enterprises requires support for their committed costs, such as those offered by commercial loans or debt restructuring plans, enabling these businesses to manage larger fixed costs until they can restore revenues. Examples of these programs include state and local programs, such as Delaware County's Strong Small Business Support Program, which provides grants specifically for the payment towards commercial lease obligations. More generally, these programs also include the newly enacted Small Business Reorganization Act of 2019 (the SBRA). The SBRA creates a new subchapter V of Chapter 11 of the Bankruptcy Code, which greatly facilitates the use of a Chapter 11 reorganization for small businesses. Under Subchapter V, a small business debtor can confirm a plan of reorganization without the consent of its long-term creditors, while allowing the debtor to maintain its ownership interest. As such, it provides small businesses who are struggling under the weight of their long-term commitments valuable leverage to renegotiate a commercial lease and other committed costs. Our findings indicate these costs are most problematic for the survival of enterprises, making these programs especially relevant for these firms.

\section{Testing POLICIES FOR SURVIVAL}

On June 3, 2020, the City of Oakland launched a follow-up survey, the Re-opening and Recovery Survey, that asked approximately three hundred business about the aid (if any) that these businesses had pursued and received as well as their short-term and medium-term projections for survival. This survey provides a novel evaluation of the impact of policy programs and an opportunity to test the heterogeneous survival challenges faced by different sized firms. In assessing this survey, we are cognizant of selection into applying to participate in a policy program as well as in survey participation. We address the issue of selection and discuss any limitations to the interpretation of our findings accordingly.

\section{A. Data \& Statistics}

Our primary interest is in two dependent variables relating to the risk of short-term closing and the ability to survive in the medium- to long-term. Both of these variables build off the survey question: "If business disruption continues at the current rate, how soon will you be at risk of permanently closing your business?” The choices for answering this question are presented in Table 8 where we present summary statistics for the follow-up survey. We construct the short-term closing variable as an indicator equal to one if a respondent either answered this question using the selection " 0 to 1 month" or indicated that the business was already closed in an open-ended question of actions taken. We construct the variable mediumrun surviving as an indicator equal to one if a respondent answered the above-referenced question by 
indicating that the business could sustain present conditions for more than 6 months. Overall, short-term closing represented $10 \%$ of the sample, while medium-run surviving businesses represented 35\%. This implies that without policy programs or improvements in the economy, the majority of respondents faced medium-run closure.

Our primary independent variables of interest are whether the business received a PPP loan and whether the business owner received Pandemic Unemployment Insurance (PUI). Under the terms of the PPP, all respondents should have been eligible to apply for a PPP loan given that the program was open to employer and nonemployer businesses having fewer than 500 employees, and all respondents reported having employee headcounts that would meet this requirement. ${ }^{10}$ Eligibility for PUI was limited to individuals who were not eligible for traditional unemployment insurance; therefore, it was available to respondents who were either nonemployer business owners or employer business owners who had laid off all employees and were seeking unemployment insurance for themselves personally. A large $59 \%$ of the survey respondents received PPP funds, with an acceptance rate of 77\%. In addition, 32.9\% of survey respondents received PUI funds, with a 68\% acceptance rate. Qualifying for PUI implies furloughing or laying off all employees—a seemingly optimal strategy for many survey respondents.

Finally, we have demographic statistics. Sixty-two of the businesses are female-owned. Half of the businesses are temporarily closed. The racial-ethnic breakdown of the sample is as follows: white (43\%), other/undisclosed/mixed race (20.9\%), Asian (17.3\%), black (11.2\%) and Hispanic (7.6\%). Given our small sample, we do not try to do analysis within these categories.

\section{B. Methodology \& Selection in Receiving PPP \& PUI}

A central concern in estimating any effect of a policy program on survival concerns selection with regard to survey completion and, especially, with regard to participating in the PPP or PUI programs. Small businesses may be experiencing differences in setting - in particular, differences in financial or economic distress - that would lead to filling out the survey or participating in the PPP or PUI programs.

The concern about selecting into the survey raises the question of generalizability but should not materially affect the analysis within that selection. The concern about selection in the taking a PPP or PUI is fundamental to inference, however.

Our identification takes advantage of (i) the existence of an applied for variable in the survey that is specific to each program, with answer choices of: "No”, "Yes - Successfully”, or "Yes - Unsuccessfully”,

\footnotetext{
${ }^{10}$ In addition to this size-based requirement, the PPP was also unavailable to businesses operating in select industries (e.g., a business primarily engaged in political or lobbying activities, businesses who derive more than a third of their revenue from gambling, etc.) and to applicants whose owners are disqualified because they are presently involved in a bankruptcy proceeding or have been convicted of committing certain felony offences. Based on review of business names in this sample, we assume that none of the respondent businesses were ineligible for these reasons.
} 
combined with (ii) the unique setting that neither policy required applicants to demonstrate financial need or lack of access to other finance. Finally, we also have (iii) interim outcome variables of the status and actions taken by business to provide selection tests and conditioning variables.

Our identification relies on the idea that variation in application success rates were likely to vary across applicants in ways that were largely orthogonal to unobservable factors affecting medium-term survival. The viability of this assertion is stronger for the PPP than the PUI. Early reports indicate that PPP applicants were often unable to acquire a PPP loan due to technological problems incurred by the applicant's bank or because its lender was otherwise unable to process the loan due to confusion over the application of bank secrecy protocols to PPP loans. ${ }^{11}$ This variation accordingly allows us to estimate the effect of the PPP à la the idea of the instrument used in Granja et al. (2020). Said more directly, in our sample, of the Oakland businesses applying for a PPP, a quarter were unsuccessful in their application attempt. The lack of success of these businesses is likely to be largely noise, given the power in the first stage of Granja et al (2020). In this regard, it is also worth reiterating that the survey did not ask business owners who applied for the PPP or PUI if they accepted or rejected funding once approved, but rather if the owner successfully or unsuccessfully applied. Overall, we believe that this approach to identification makes it plausible to isolate a causal effect of the PPP on business medium-run outcomes. That said, in the discussion below, we refrain from using this language, as our sample is small, and we cannot prove the randomness of the PPP application success or unsuccess of the Oakland businesses.

Our first use of the applied for variable is through a simple selection test that examines whether businesses that were successful in applying for a PPP loan or PUI differed in setting. We use the applied for variable in combination with information on the businesses' current operating status and an action taken variable to test for residual selection in successfully applying for a PPP or PUI beyond the decision to apply. The operating status variable is the answer to the question of whether the business (in June, 2020) is open, reduced, or closed in its business operations. The action taken variables provide information on whether and how a business has adjusted to the crisis with answers of: "furloughing employees” (20.1\%), "having employees work remotely” (18.0\%), “no action” (13.3\%), “reduced employees’ hours” (10.4\%), and "laid off employees" (7.9\%). We note that some of the differences in these interim status and action variables may be an outcome of the PPP, as early June is after the PPP's first wave and some of the second wave.

\footnotetext{
${ }^{11}$ For instance, lack of guidance from the SBA caused banks to vary in the stringency with which they applied the Bank Secrecy Act to loan applicants, which could result in a PPP denial. See Douglas Jensen and Jeremy Kuester, "Payroll Protection Program and the Bank Secrecy Act: Balancing Aid to Small Businesses with Financial Crime Risks,” White \& Case Memo, April 17, 2020. Banks also experienced difficulties in processing PPP loan applications due to problems accessing the SBA's overwhelmed E-Tran portal. See “Banks Report E-Tran Difficulties; SBA Lowers PPP Bulk Submission Threshold,” ABA Banking Journal, April 27, 2020.
} 
Yet, we prefer to err on over-control for this possibility, rather than over-interpret our medium-run survival results.

Table 9 presents selection tests. The dependent variable in columns 1-2 is an ordered logit specification of current status: closed < reduced < open. The dependent variables in columns 3-10 are the action taken options listed above, cast as indicator variables for each answer. In the odd columns of the table, we include only indicators for whether a business successfully applied for the PPP or PUI, plus industry fixed effects. In the even columns, we include variables for applying for each program, allowing us to gauge the selection of applying versus application success. At the bottom of the table, we do the addition of the two coefficients (because success is the union of applying for the program and succeeding), and show the significance test.

We find, that successfully applying for the PUI is highly endogenous to intermediate status. This is not terribly surprising, since the businesses with employees generally must eliminate all employees in order to qualify as a nonemployer. We see this result in the ordered logit of current status, as well as on the indicator for the action taken of "having employees work remotely."

However, the PPP results are quite different. Focusing on the even-numbered columns, we find that although the current status and the action taken are associated with success in a PPP application in some columns, these effects are generally offsetting to the coefficient for applying-for a PPP. Granted, such an offsetting pattern is associated with collinearity concerns, but we also show the same pattern results without the Applied PPP variable. The only interim variable that suggests a concern is the "furloughing employees" variable. In the survival analysis below, we therefore present results with and without businesses that express this interim action.

\section{PPP \& PUI Results}

Table 10 presents estimates for our policy tests. Columns 1-3 examine the association between policy program application success and short-term permanent closure; columns 4-7 examine the association between application success and medium-term survival. All columns include industry, gender identity, and race/ethnicity fixed effects. We discuss each policy in turn.

We find that application success for the PPP has no association with short-term closure, consistent with the results of Chetty et al. (2020) and Granja et al. (2020). Column 1 presents the results excluding the indicators for whether a business applied for either program, to be able to compare magnitudes when absorbing any selection in applying, which we add in column 2. Column 3 differs from column 2 in that we use a linear probability model to show that the selection of the perfectly-determined variables in the logit (which drop from the estimation) are not influential (note the difference in observations). We find no result relating the PPP to short-term closure with or without the application variable. 
However, the results are quite different with respect to medium-term survival. Success in a PPP application increases medium-run survival probability by $27 \%$ in column 4 . In column 5 , the result holds when we add the application indicators to address selection. The result continues to hold when we drop furloughing firms (column 6) and when we add in controls for interim status and actions taken (column 7). The sum of the coefficients for Applied PPP and Success PPP in column 5 is 0.205, suggesting that our efforts to address selection diminishes the effect of the PPP on increasing medium-run survival by $27 \%$ to $20.5 \%$.

The finding that a PPP application success is strongly associated with increasing firm survival in the medium run by $20.5 \%$ is in stark contrast to the implications that the PPP was ineffective, as in the employment results in Chetty et al. (2020) and Granja et al. (2020). The difference is surely due to our being able to study medium-run effects (and even control for short-term status) and to the fact that prior work has focused on larger small businesses. Consistent with us, Granja et al. (2020) foreshadows our finding insofar that businesses taking the PPP in their sample note that they are either making productive use of the capital or saving for survival purposes. We confirm their intuition.

Our second main result on the PPP effect concerns heterogeneous effects by firm size. Looking at the interaction of LogWorkers and the PPP success indicator, we find that as businesses increase in employee count, the PPP is no longer associated with staving off closure. Again, we are cognizant that selection could differentially affect firms of different sizes, but note that the selection story on the interaction is one of differential status by firm size, whose sign is likely to suggest our interaction results are conservative. ${ }^{12}$

The Oakland data thus reveal heterogeneous effects of the PPP on medium-term closure risk by firm size. Using the estimates from column 7, we plot this pattern in Figure 8, noting that the effect becomes economically immaterial after approximately 20 employees. Note that in 2015 census data, 92.9\% of businesses and $17 \%$ of employment are in businesses under 20 employees.

In addition to this result being consistent with Granja et al. (2020) (who find no overall effect on closure rates among larger small businesses receiving PPP loans), this result is a test of our compatibility findings. We suggested earlier in this section that labor cost supporting programs would be less effective for

\footnotetext{
${ }^{12}$ This interaction finding gives direction to the rival selection story and affords us a partial test. In particular, for this interaction effect to be the product of selection, it must be the case that, among PPP recipients, revenues for larger enterprises are sufficiently distressed that these enterprises are likely to close in medium-term. Conversely, revenues for microbusinesses that receive PPP loans must be sufficiently strong that they are likely to remain open. To examine whether this is the case, we test the association between operating status (Open>Reduced $>$ Closed) and LogWorkers and its interaction with whether a respondent successfully applied for a PPP loan, holding constant industry effects. The results (unreported) reveal a significant interaction between LogWorkers and PPP success, indicating that (if anything) enterprises were experiencing stronger revenues than microbusinesses, the opposite of what would be required for selection to drive this result.
} 
enterprises, because these organizations use labor flexibility as their survival strategies. This result confirms this intuition.

Turning to the PUI results, we find an opposite pattern. PUI success is negatively associated with shortterm closure, but has no association with medium-term survival. In the short-term, business owners that were successful in their PUI application shuttered their operations with a 9.4\% to $19.1 \%$ lower probability, suggesting that owners were relying on the PUI to replace their lost business income to remain in operation. However, this result does not hold for the larger enterprises, as we see that the coefficient on LogWorkers interacted with the PUI indicator is positive. This latter result should be expected: Recall that for larger firms, taking PUI implies that the business had to first lay off all workers. Thus, this unwinding of the effectiveness of the PUI for these businesses is a mingling of the selection of already-struggling business to apply for PUI with the inability of the PUI's income substitution (roughly $\$ 600$ per week) to support the owner of a business that has lost so much revenue that it has presumably let go of all of its employees.

\section{CONCLUSION}

The bundling of small businesses into one category is too coarse for designing small business assistance programs during periods of macro distress. Using a unique set of data, we show that in Oakland, small businesses, all facing distress during the COVID-19 pandemic, have notably different survival capabilities concerning strategies focused on revenue resilience, labor flexibility and committed costs. Moreover, these survival capabilities differ systematically by the size of a firm.

Our punchline, however, is not simply that these differences exist, but also that they have significant policy relevance with regard to the design of small business assistance programs. The PPP provides an especially costly example of this basic point. Designed as a $\$ 610$ billion program to assist U.S. small businesses, the PPP loan forgiveness requirements effectively made the program a labor subsidy. To our knowledge, we are the first to show the effectiveness of the PPP, but we also show that the labor-focused strategy of the PPP runs counter to the survival capabilities of larger enterprises that focus on scaling back labor costs.

Our framework also provides an important tool for researchers in evaluating the effectiveness of small business assistance programs. Again, the PPP and early studies of its effect on small business payrolls provides an example. As noted, Chetty et al. (2020) find that the PPP had no meaningful impact on employment rates, leading these authors to conclude that liquidity is insufficient to restore employment at small businesses. By focusing on enterprises having an average of 45 employees or more, however, the study's data would not have been able to identify heterogeneous treatment effects for the PPP within the universe of small businesses. As we show, expressly grappling with the different survival capabilities of 
microbusinesses highlights how labor subsidies are likely to be especially helpful to these firms, while being less helpful to the enterprises studied by Chetty et al.

Finally, our findings speak to the broader policy question of how to optimally support small businesses through a crisis given existing evidence that different sized small businesses have differential welfare effects. In particular, researchers examining growth patterns among small businesses have highlighted considerable heterogeneity regarding the growth prospects of small businesses, particularly as between employer and nonemployer businesses (Decker et al. (2014) and Hurst and Pugsley (2011)). Differences likewise exist in the extent to which small businesses contribute to community vibrancy. In combination, these findings provide good reason for policymakers concerned with promoting job growth to focus on assisting those small businesses we classify as enterprises, while those concerned with community vibrancy and local tax bases would be well-advised to focus on assisting nonemployers and microbusinesses.

While it is beyond the scope of this paper to address how to prioritize these competing considerations, we view our findings as providing two pieces of information that is critical to its resolution. The first concerns the importance of mapping specific programs to the desired beneficiaries of small business support programs. As we show, differentials in survival capabilities across firms have implications for how to best support firms of different sizes; that is, while labor subsidies may be effective for supporting microbusinesses, facilitating lease forgiveness may be more effective for larger enterprises.

The second relates to the temptation to focus exclusively on job growth in the design of small business survival, particularly given the fiscal costs these programs can entail. Within our data, we find that the survival capabilities of nonemployers and microbusinesses provide welfare effects that would be imprudent to dismiss. It is the microbusinesses that are most revenue resilient, despite their need to cover a lessflexible labor cost structure. They are more-than pulling their weight in supporting the local economy during the COVID-19 crisis insofar that they have revenue resilience. This revenue resilience translates to income to support the local economy through preserved returns to labor and sales receipts, as well as to their (small) property bases. Similarly, nonemployer proprietors, either because of their greater economic flexibility or the potential to realize non-monetary utility from operations, may be more likely to choose to continue operations regardless of the level of demand for their services. These businesses may not support the labor force or sales/business taxes with their low-return businesses, but to the extent that they are central to establishment proliferations (Hurst and Pugsley 2010) and to the extent that establishments lead to community vibrancy, these businesses' self-effort and sometimes self-funded resiliency is valuable to the community.

In short, the framework we provide should enable policy makers to design small business support programs that are both better informed and more effective in achieving the welfare objectives that justify their creation. 


\section{REFERENCES}

Adams, Abi, Teodora Boneva, Marta Golin, and Christopher Rauh, "Inequality in the Impact of the Coronavirus Shock: Evidence from Real Time Surveys,” Technical Report, Mimeo 2020.

Alm, James, Robert D. Buschman, and David L.Sjoquist, 2014. "Foreclosures and local government revenues from the property tax: The case of Georgia school districts.” Regional Science and Urban Economics Volume 46, May 2014, Pages 1-11

Austin, Benjamin, Edward Glaeser, and Lawrence Summers, 2018. "Saving the Heartland: Place-based Policies in $21^{\text {st }}$ Century America.” Brookings Papers on Economic Activity Brookings Papers on Economic Activity, vol 2018(1), 151-255.

Bartik, Alexander W., Marianne Bertrand, Zoe Cullen, Edward L. Glaeser, Michael Luca, and Christopher Stanton, "How are small businesses adjusting to COVID-19? Early Evidence from a Survey," NBER working paper, 2020, (26989)

Bhutta, Neil, Jacqueline Blair, Lisa Dettling, and Kevin Moo, 2020. "COVID-19, the CARES Act, and Families’ Financial Security.” Working Paper.

Chetty, Raj, John Friedman, Nathaniel Hendren, Michael Stepner, and The Opportunity Insights Team, 2020. "How Did COVID-19 and Stabilization Policies Affect Spending and Employment? A New RealTime Economic Tracker Based on Private Sector Data,” Working paper.

Davis, Steven, John Haltiwanger, Ron Jarmin, C.J. Krizan, Javier Miranda, Alfred Nucci, Kristin Sandusky (2007). "Measuring the Dynamics of Young and Small Businesses: Integrating the Employer and Nonemployer Universes." NBER Working Paper 13266.

Davis, Stephen J., John Haltiwanger, and Scott Schuh, 1996, Job Creation and Destruction. Cambridge, Massachusetts: MIT Press.

Decker, Ryan, John Haltiwanger, Ron Jarmin, and Javier Miranda, 2014. "The Role of Entrepreneurship in US Job Creation and Economic Dynamism.” Journal of Economic Perspectives, 28 (3): 3-24

Freedman, Robert. 2020. 75\% payroll rule makes PPP loans useless, business owners say, CFO Dive, available at https://www.cfodive.com/news/payroll-rule-paycheck-protection-program-uselesscoronavirus/577213/.

Granja, João , Christos Makridis, Constantine Yannelis, and Eric Zwick (2020). "Did the Paycheck Protection Program Hit the Target?”, working paper.

Haltiwanger, John, Ron S. Jarmin, and Javier Miranda. 2013. "Who Creates Jobs? Small vs. Large vs. Young.” Review of Economics and Statistics 95(2): 347-61.

Hurst, Erik and Benjamin Wild Pugsley. 2011. "What Do Small Businesses Do?” Brookings Papers on Economic Activity 2011 (2): 73-118.

Humphries, John Eric, Christopher Neilson and Gabriel Ulyssea, “The Evolving Impacts of Covid-19 on Small Businesses Since the Cares Act”, Cowles Foundation Discussion Paper No. 2230, April 2020. 
Iverson, Ben, Raymond Kluender, Jialan Wang, and Jeyul Yang, 2020. "Bankruptcy and the COVID-19 Crisis.” Working Paper.

Mayer, Colin, Donald S. Siegel, and Mike Wright, 2018. “Entrepreneurship: An Assessment.” Working Paper.

Moskowitz, Tobias and Annette Vissing-Jorgensen, 2002. “The Returns to Entrepreneurial Investment: A Private Equity Premium Puzzle? American Economic Review.

Rajan, Raghuram, 2020. "Businesses cannot simply awake from this coma and carry on.” Financial Times. May 12, 2020.

Small Business Administration, 2018, A Look at Nonemployer Businesses, available at https://www.sba.gov/sites/default/files/advocacy/Nonemployer-Fact-Sheet.pdf.

Small Business Administration, 2020, Applying for Economic Injury Disaster Loans , available at https://www.sba.gov/sites/default/files/resource_files/EIDL-BDO_Presentation_March_26_0.pdf.

Shoag, Daniel and Stan Veuger, 2018. "Shops and the City: Evidence on Local Externalities and Local Government Policy from Big-Box Bankruptcies.” The Review of Economics and Statistics 2018 100:3, 440-453.

Tierney, Kathleen J. and James M. Dahlhamer, 1998, "Rebounding from Disruptive Events: Business Recovery Following the Northridge Earthquake.” Sociological Spectrum 18(2)

Tsivanidis, Nick and Michael Gechter, 2019. Spatial Spillovers from Urban Renewal: Evidence from the Mumbai Mills Redevelopment, Working Paper 


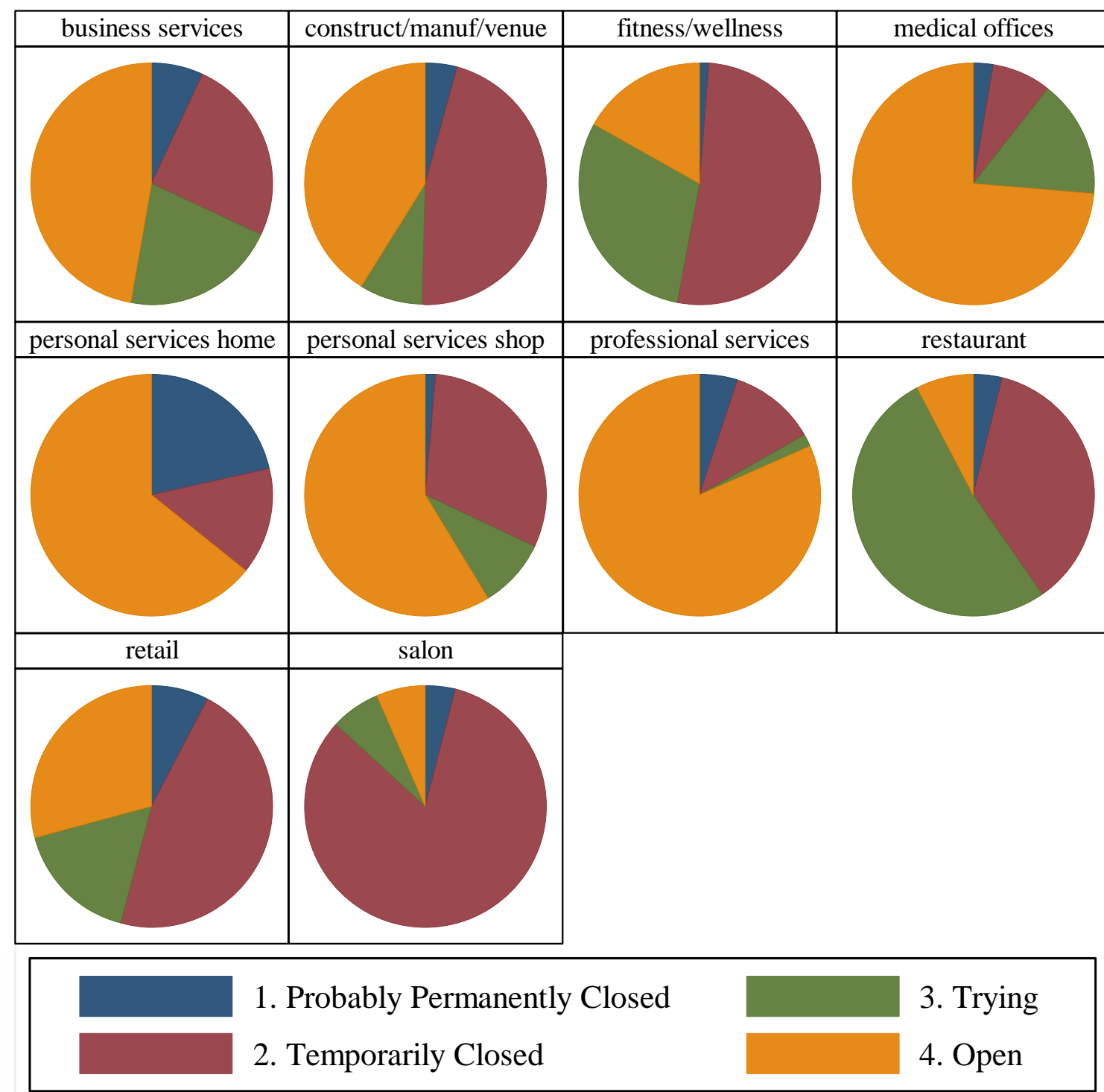

\section{Figure 1: Interim Outcome Status Outcomes by Industry}

Depicted are the interim outcomes via the manual search data for the City of Oakland firms as of the last week of April, 2020. Trying indicates that the business is working on a reduced or alternative revenue model, and is otherwise temporarily closed. Probably Permanently Closed indicates that the business is either marked permanently closed in Google Maps, the company website, or Yelp, or the business shows no information as to being a going concern. 


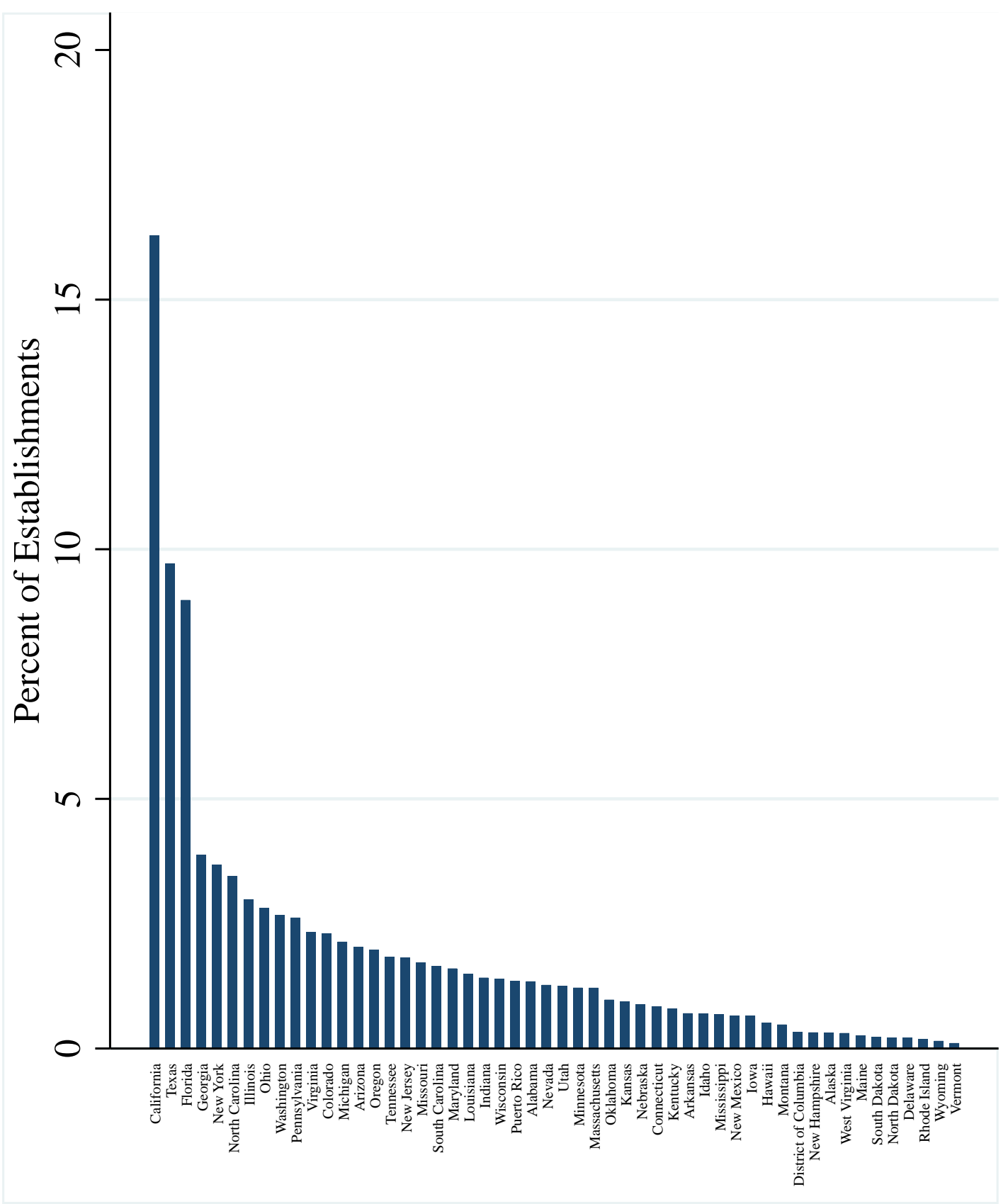

FIGURE 2: Distribution of HomeBase Establishments by State

Figure reports by state the percent of establishments located within the state across all establishments within our sample of HomeBase establishments. Reported state of location is provided by HomeBase. 
SafeGraph Devices in the United States

total devices by county

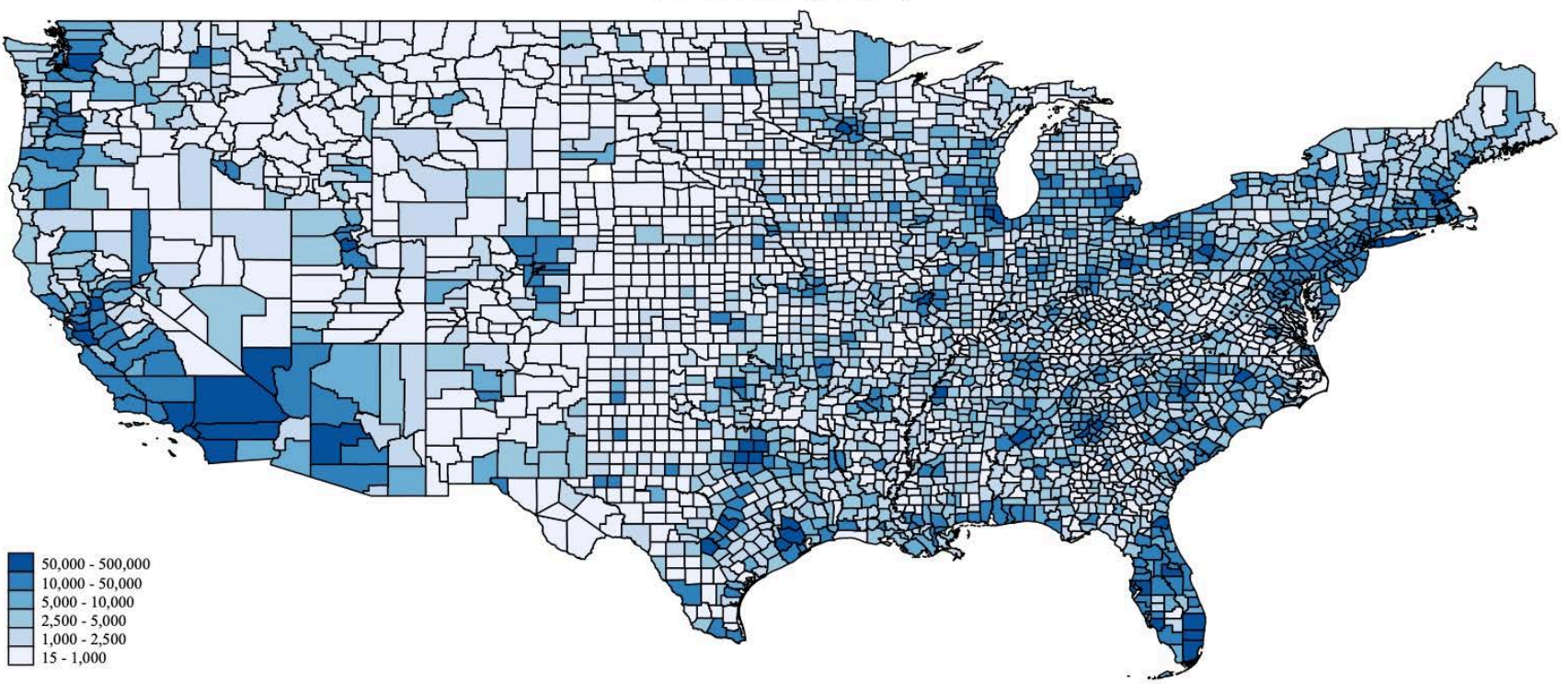

\section{SafeGraph Devices in California}

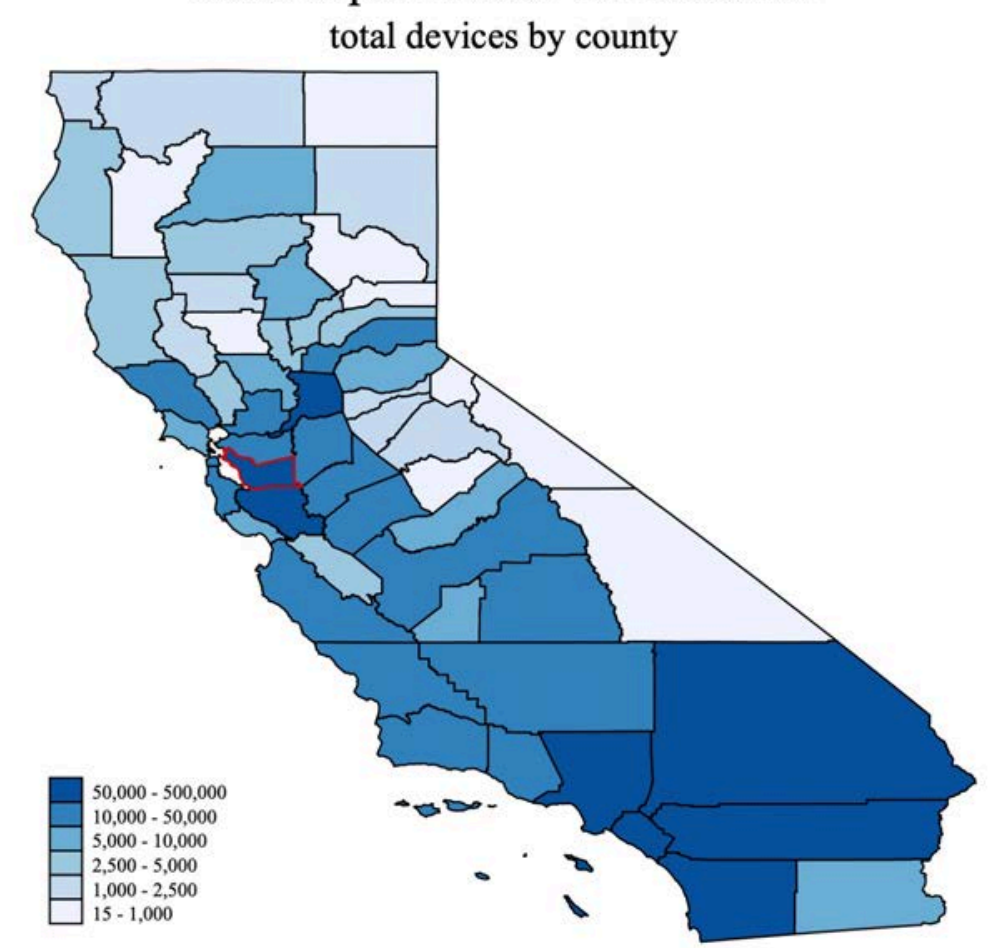

FIGURE 3: Distribution of SafeGraph Devices Nationally and Within California

Figure presents by county the mean number of mobile devices observed by SafeGraph between January 1, 2020 and April 30, 2020. The upper panel presents national data while the lower panel provides an enlarged figure for California. Alameda county is outlined in red. 


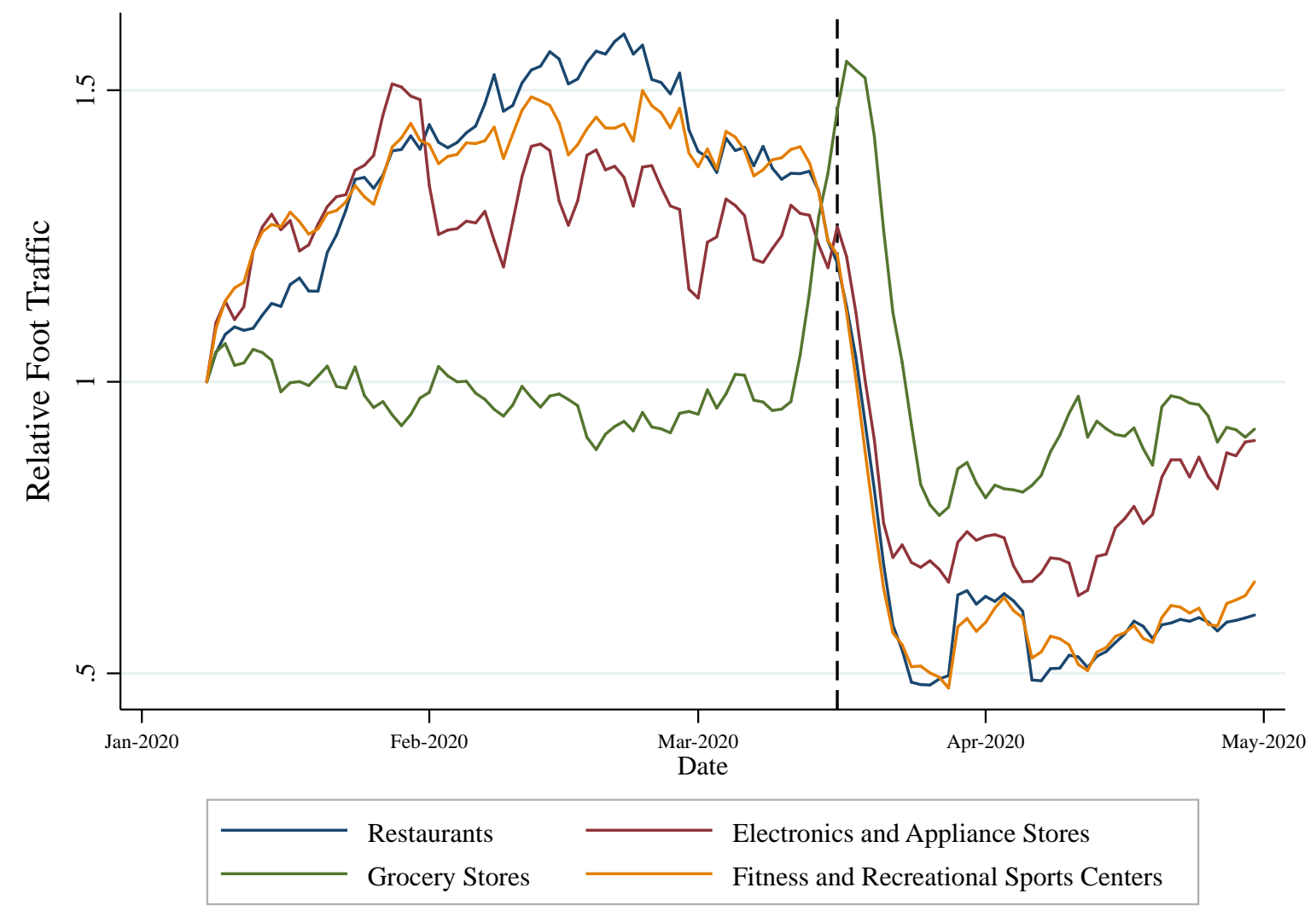

FIGURE 4: Impact of Shelter-in-Place Order on Select Alameda County Businesses Figure illustrates the mean change in foot traffic for Alameda County businesses relative to foot traffic for a business on January 8, 2020. Foot traffic data are from SafeGraph and reflect observed daily visits to a Safegraph POI located within Alaemda County. Due to variation in daily foot traffic visits, visits per location are measured as the moving average over the preceding seven-day period. 


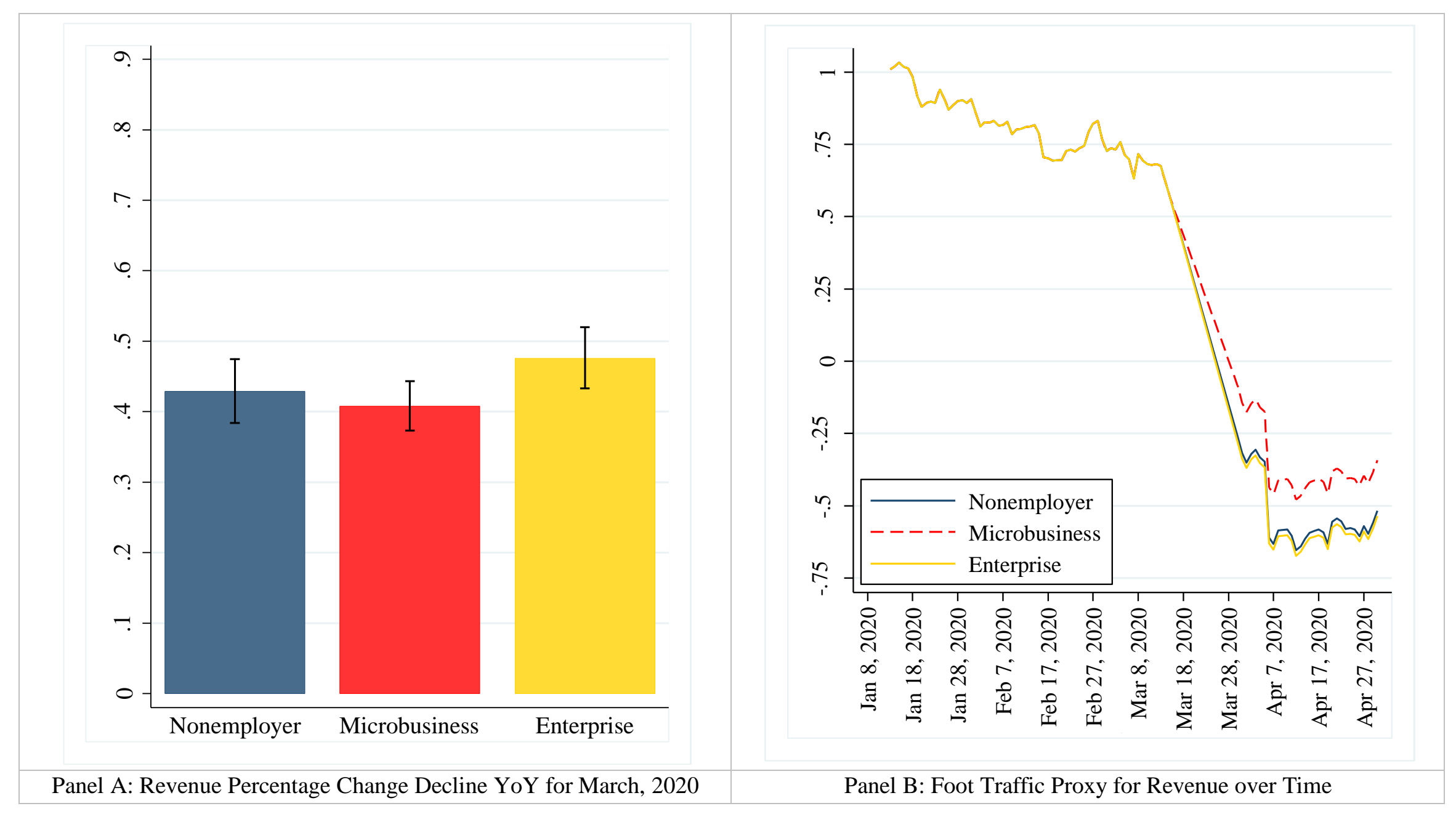

FIGURE 5: Revenue Resiliency by Small Business Type

The sample in both panels are the small businesses in Oakland covered by the City of Oakland COVID-19 Small Business Survey. Panel A plots the predicted percentage change decline in employees by small business type resulting from column 4 of Table 4 . The sample in Panel B are Oakland businesses are matched to SafeGraph POIs. Plotted are the predicted foot traffic (relative to January 8, 2020) over time by small business type resulting from the difference-in-difference estimate of column 6 of Table 4, absorbing (subtracting out) the firm fixed effects. 


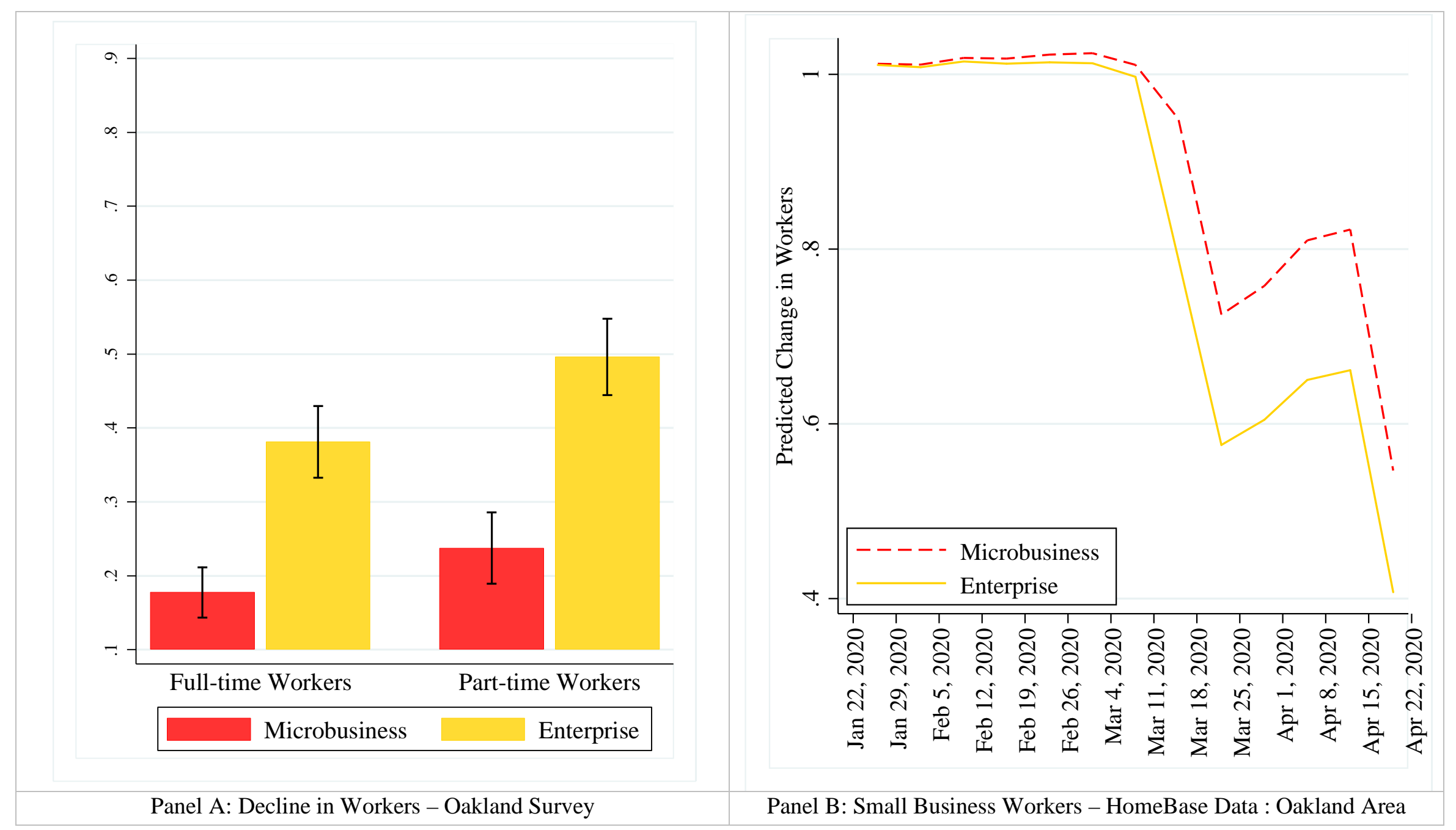

\section{FIGURE 6: Labor Flexibility by Small Business Type}

The sample in Panel A are the small businesses in Oakland covered by the City of Oakland COVID-19 Small Business Survey. Plotted is the predicted decline in employees by small business type resulting from columns 2 and 4 of Table 5. The sample in Panel B is the predicted time series for Oakland area (zip code 94XXX) small businesses covered by Homebase from column 3 of Table 6. 

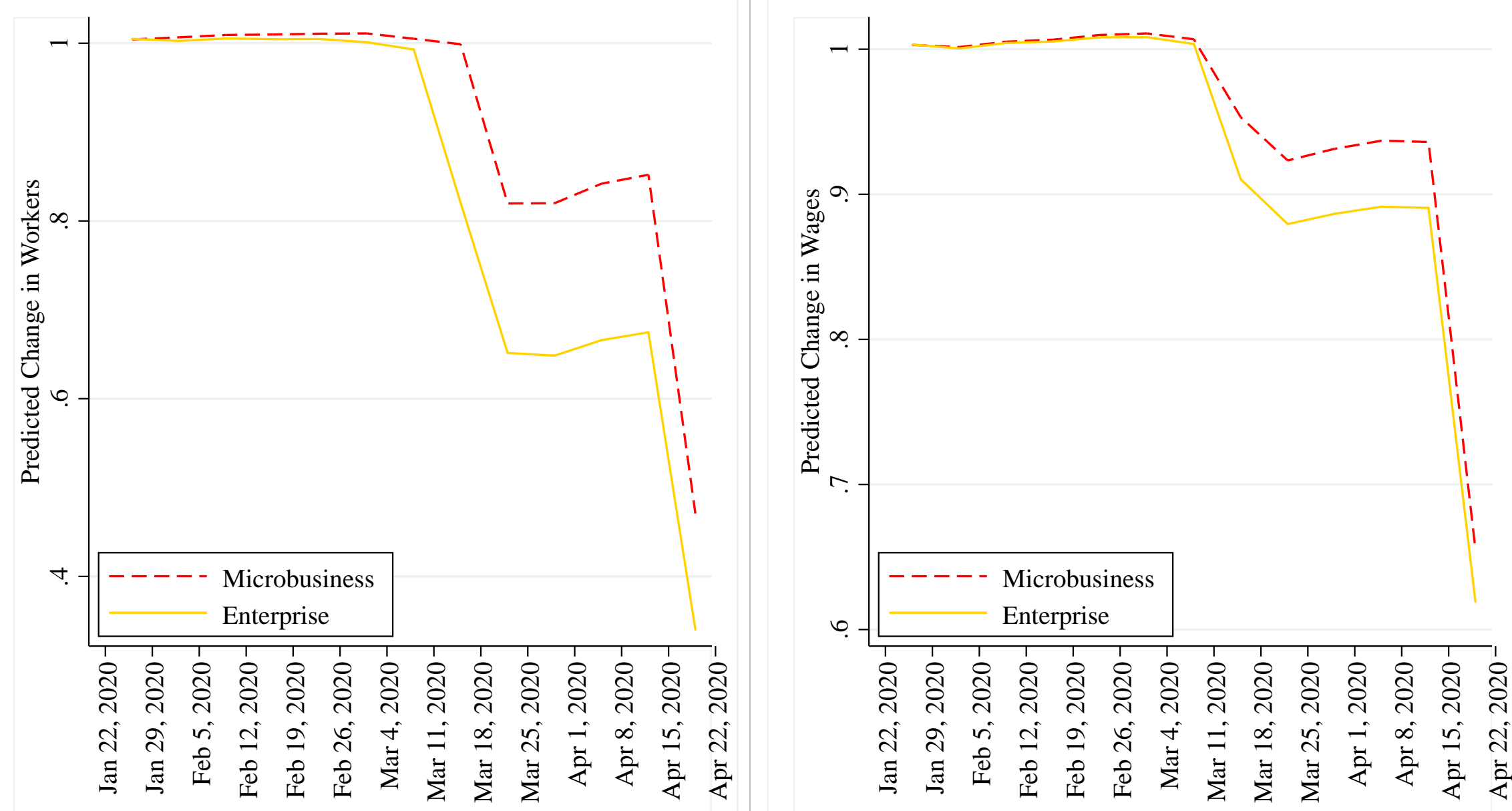

Panel C: Small Business Workers - Homebase National

Panel D: Small Business Payroll - HomeBase National

\section{FIGURE 6: (continued) Labor Flexibility by Small Business Type}

The sample are all U.S. business establishments covered by Homebase. Plotted is the predicted decline in workers (Panel C) and wages (Panel D) by small business type resulting from columns 6 and 9 of Table 6. 


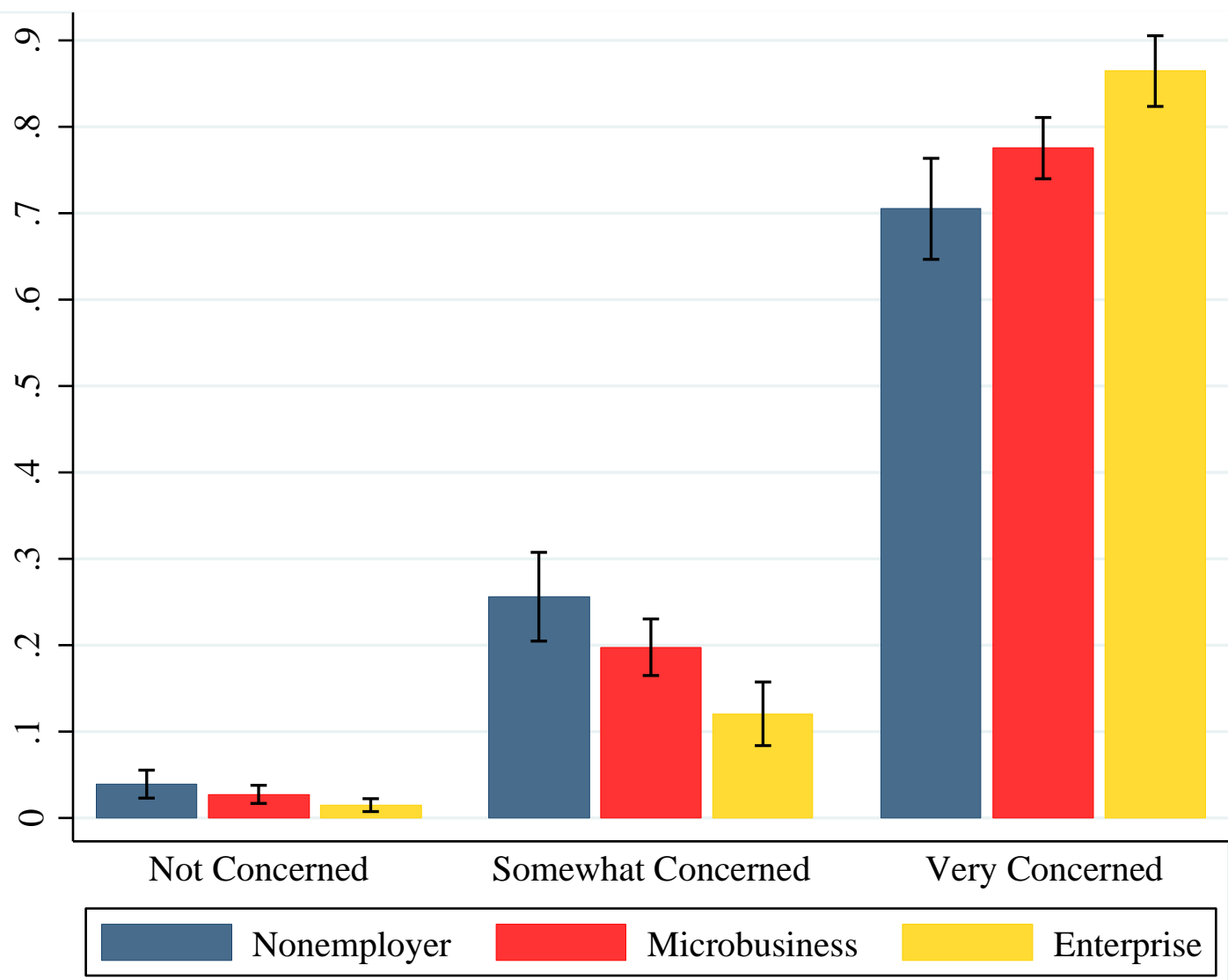

FIGURE 7: Residual Closure Risk (Committed Costs) by Small Business Type

The sample is the City of Oakland COVID-19 Small Business Survey. Plotted is the predicted effect of firm size on closure risk, specifically of stating that one's concern for closure risk is not concerned, somewhat concerned, or very concerned, from the ordered logit estimation of Column 4 of Table 7. 


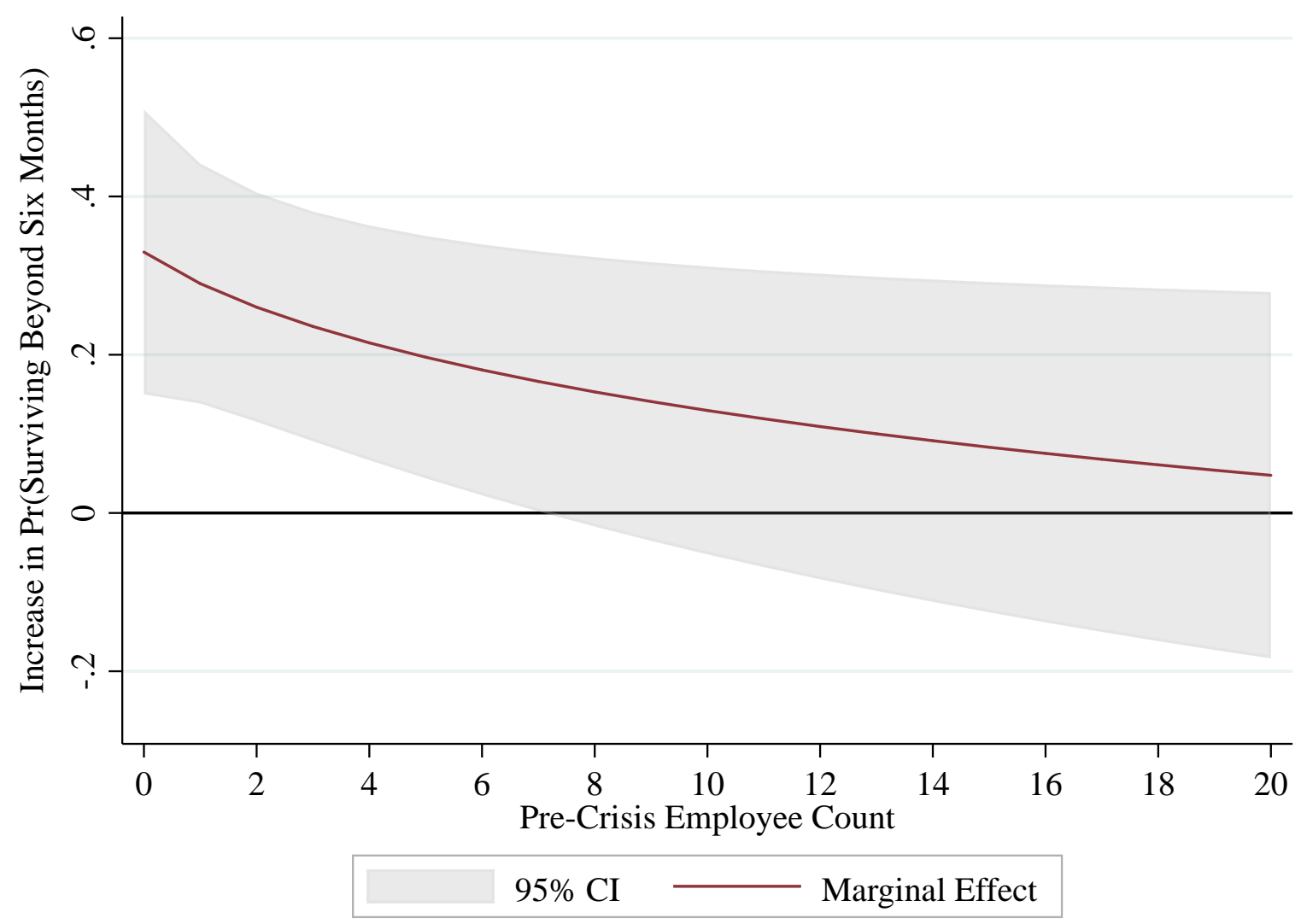

FIGURE 8: Effect of Payroll Protection Program (PPP) on Medium-run Survival

The sample is the City of Oakland COVID-19 Small Business Survey. Plotted is the predicted effect of firm size on medium-run survival, measured as the response to the question asking if circumstances do not change, how long can your firm survive from column 5 of Table 10, and taking into account the coefficients on Applied PPP, Success PPP, and Success PPP*LogEmployees. 
Table 1: City of Oakland COVID Survey of Small Business Summary Statistics

All data in Table 1 are from the City of Oakland COVID Survey of Small Business. Our sample is from March 13, 2020 to April 1, 2020. As reported in Panel A, Nonemployer, Microbusiness and Enterprise classifications are indicator variables dividing the sample into those with no employees, those with 1-5 employees, and those with 6-50 employees, respectively. Employees are reported as exisitng in early March (pre-crisis). The smaller sample in Panel A, 761 firms, are those with positive employment. For this sample, we know the existing base of part-time and full-time employees and the jobs lost. Panel B presents two pictures of gross receipts. First is whether the business is declining in gross receipts, defined as reporting the year-over-year receipts as of February as being in decline relative to 2019. A smaller sample responded to the question as to the declines in March at the initial sheltering in place. The survey asked owners to report their gross receipts in March year-over-year from March 2019. Panel C presents closure risk responses. In particular, the survey respondents were asked how concerned they were about closing the business, responding in the categories listed below.

\begin{tabular}{|c|c|c|c|c|c|c|c|c|}
\hline \multicolumn{9}{|l|}{ Panel A: Employment } \\
\hline & Obs & Mean & StDev & $0 \%$ ile & 25\%ile & 50\%ile & 75\%ile & 100\%ile \\
\hline Nonemployer & 1,014 & 0.250 & 0.433 & 0 & 0 & 0 & 0 & 1 \\
\hline Microbusiness & 1,014 & 0.430 & 0.495 & 0 & 0 & 0 & 1 & 1 \\
\hline Enterprise & 1,014 & 0.321 & 0.467 & 0 & 0 & 0 & 1 & 1 \\
\hline Employees & 1,014 & 6.52 & 9.81 & 0 & 1 & 2 & 8 & 50 \\
\hline \multicolumn{9}{|c|}{ If microbusiness or enterprise... } \\
\hline Employees & 761 & 8.68 & 10.46 & 1 & 2 & 4 & 11 & 50 \\
\hline Full-time Employees & 761 & 4.46 & 6.70 & 0 & 1 & 2 & 5 & 48 \\
\hline Part-time Employees & 761 & 4.22 & 6.75 & 0 & 0 & 2 & 5 & 40 \\
\hline \% Change Jobs Lost & 761 & 0.177 & 0.256 & 0 & 0 & 0 & 0.421 & 1 \\
\hline
\end{tabular}

\section{Panel B: Gross Receipts}

Declining

$\begin{array}{lccc}<2 \% & 6 & 0.007 & 0.007 \\ 2-5 \% & 7 & 0.008 & 0.015 \\ 5-10 \% & 30 & 0.035 & 0.050 \\ 10-20 \% & 53 & 0.061 & 0.111 \\ 20-40 \% & 168 & 0.194 & 0.306 \\ >40 \% & 600 & 0.694 & 1.000\end{array}$

\section{Panel C: Business Closing Risk}

How concerned are you about your business closing?

Answers:

Not Concerned

\begin{tabular}{ccc} 
Obs & Percentage & Cumulative Percentage \\
\hline 40 & 0.039 & 0.039 \\
233 & 0.230 & 0.269 \\
741 & 0.731 & 1.000 \\
\cline { 3 - 3 } 1,014 & 1.000 &
\end{tabular}




\section{Table 2: Oakland Manual Data Collection Summary Statistics}

Presented are the manual lookup data for businesses in the City of Oakland COVID Survey. We manually coded all fields -- industry, location, whether the business is essential under Alameda County's shelter-in-place order, and outcome status by a two step process. We always invoke both steps. First we looked up the establishment in Google Maps. Second, we went the to business website (always) and other Internet sites where information might be available (if necessary), including yelp and blogs of closures.

\begin{tabular}{|c|c|c|c|}
\hline \multicolumn{4}{|l|}{ Panel A: Industry } \\
\hline & Obs & Percentage & Examples \\
\hline Business services & 82 & $8.1 \%$ & Catering, industrial cleaning, printing, photography, technolog \\
\hline $\begin{array}{l}\text { Construction / fabrication } \\
\text { / venues / workspaces }\end{array}$ & 95 & $9.4 \%$ & $\begin{array}{l}\text { Construction, entertainment venues, event spaces, parking } \\
\text { lots, housing, manufacturing, wholesale trade }\end{array}$ \\
\hline Fitness / gym / wellness & 86 & $8.5 \%$ & Fitness centers, gyms, massage, acupuncture \\
\hline Medical offices & 38 & $3.7 \%$ & Chiropractic, dentist, optical, physical therapy, psychology \\
\hline Personal services home & 28 & $2.8 \%$ & Home repair, landscape, pet walking, realty \\
\hline Personal services shop & 75 & $7.4 \%$ & Auto repair, car wash, child care, education, laundry, tattoo \\
\hline Professional services & 206 & $20.3 \%$ & Architects, consultants, desginers, engineers, lawyers \\
\hline Restaurant & 156 & $15.4 \%$ & Restaurants \\
\hline Retail & 144 & $14.2 \%$ & Retail shops \\
\hline \multirow[t]{2}{*}{ Salon } & 104 & $10.3 \%$ & Salons, barbers \\
\hline & 1,014 & $100.0 \%$ & \\
\hline
\end{tabular}

\section{Panel B: Commerce Location and Essential Designation}

Main Street

\begin{tabular}{cc} 
Obs & Percent \\
\hline 674 & 0.665
\end{tabular}

At a Venue, Home, or Offsite

\begin{tabular}{cc}
340 & 0.335 \\
\hline 1,014 & 1.000
\end{tabular}

Essential Business under Shelter-in-Place

$1,262 \quad 0.110$

Panel C: Interim Outcome
Permanently Closed or Lacking Ongoing Concern Signal
Temporarily Closed
Trying
Open

\begin{tabular}{ccc} 
Obs & Percent & Cumulative Percent \\
\hline 159 & 0.192 & 0.192 \\
211 & 0.255 & 0.447 \\
172 & 0.208 & 0.655 \\
285 & 0.345 & 1.000 \\
\cline { 1 - 2 } 827 & 1.000 & \\
\hline
\end{tabular}


Table 3: Homebase Employee Data and SafeGraph Foot Traffic Data Summary Statistics

Panel A presents summary statistics for the sample of small businesses provided by HomeBase, tabulated separately by HomeBase industry. Columns 1 - 4 present mean and median employee headcount during the period January 1, 2020 and February 15, 2020. Columns 5-8 present statistics for total weekly wages during this same time period for those firms within HomeBase that reported wages for some or all employees. Panel B presents summary statistics by coded industry for daily foot traffic for 268 small businesses in the Oakland survey that could be matched to a Point of Interest (POI) within the SafeGraph dataset. Daily foot traffic is defined as reported visits per day to a POI between January 1, 2020 and March 15, 2020, scaled by the number of devices observed by SafeGraph in Alameda County per 100,000 residents.

\begin{tabular}{|c|c|c|c|c|c|c|c|c|}
\hline \multicolumn{9}{|c|}{ Panel A: Homebase Employee Headcounts } \\
\hline & $(1)$ & $(2)$ & (3) & (4) & (5) & $(6)$ & $(7)$ & (8) \\
\hline & \multicolumn{4}{|c|}{ Employees } & \multicolumn{4}{|c|}{ Weekly Wages } \\
\hline Homebase Industry & Obs & Mean & StDev & $50 \%$ ile & Obs & Mean & StDev & 50\%ile \\
\hline Beauty \& Personal Care & 417 & 4.34 & 4.29 & 3.0 & 235 & $\$ 1,093$ & $\$ 1,344$ & $\$ 692$ \\
\hline Charities, Education \& Membership & 1,430 & 8.55 & 8.16 & 6.0 & 1,013 & $\$ 2,084$ & $\$ 3,298$ & $\$ 1,168$ \\
\hline Food \& Drink & 23,159 & 9.21 & 7.41 & 7.3 & 16,761 & $\$ 2,491$ & $\$ 2,742$ & $\$ 1,731$ \\
\hline Health Care and Fitness & 3,934 & 5.57 & 5.44 & 4.0 & 2,520 & $\$ 2,086$ & $\$ 2,782$ & $\$ 1,189$ \\
\hline Home and Repair & 579 & 5.10 & 5.82 & 3.2 & 409 & $\$ 2,574$ & $\$ 3,290$ & $\$ 1,753$ \\
\hline Leisure and Entertainment & 936 & 7.91 & 7.95 & 5.3 & 735 & $\$ 2,038$ & $\$ 2,523$ & $\$ 1,175$ \\
\hline Other & 4,189 & 7.09 & 7.48 & 4.5 & 2,972 & $\$ 2,725$ & $\$ 4,522$ & $\$ 1,468$ \\
\hline Professional Services & 1,986 & 5.07 & 5.88 & 3.2 & 1,333 & $\$ 2,470$ & $\$ 4,817$ & $\$ 1,183$ \\
\hline Retail & 8,649 & 5.46 & 5.13 & 4.0 & 5,962 & $\$ 2,397$ & $\$ 3,464$ & $\$ 1,354$ \\
\hline Transportation & 373 & 6.79 & 7.43 & 4.2 & 261 & $\$ 3,577$ & $\$ 4,741$ & $\$ 1,859$ \\
\hline Unknown & 4,797 & 7.19 & 6.46 & 5.2 & 3,262 & $\$ 2,157$ & $\$ 2,797$ & $\$ 1,282$ \\
\hline All & 50,449 & 7.60 & 6.98 & 5.5 & 35,463 & $\$ 2,413$ & $\$ 3,197$ & $\$ 1,510$ \\
\hline
\end{tabular}

Panel B: SafeGraph Foot Traffic

Industry

Obs Mean StDev $\quad 0 \%$ ile $\quad 25 \%$ ile $\quad 50 \%$ ile $\quad 75 \%$ ile $\quad 100 \%$ ile

Business services

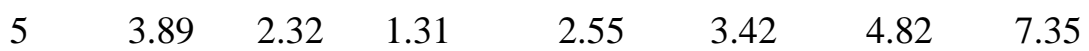

Construction / fabrication / venues /

workspaces

Fitness / gym / wellness

Medical offices

Personal services

Professional services

Restaurant

Retail

Salon

Total

\begin{tabular}{cccccccc}
5 & 3.89 & 2.32 & 1.31 & 2.55 & 3.42 & 4.82 & 7.35 \\
19 & 6.54 & 5.54 & 0.41 & 1.31 & 5.01 & 11.64 & 16.15 \\
28 & 4.83 & 4.65 & 0.35 & 1.23 & 3.37 & 7.48 & 18.25 \\
4 & 0.85 & 0.43 & 0.46 & 0.56 & 0.74 & 1.14 & 1.46 \\
14 & 5.73 & 5.50 & 0.69 & 1.96 & 4.85 & 6.63 & 21.47 \\
7 & 5.12 & 7.51 & 0.56 & 0.68 & 2.54 & 4.20 & 21.85 \\
114 & 7.55 & 8.31 & 0.10 & 3.31 & 5.37 & 8.46 & 59.68 \\
67 & 4.90 & 4.45 & 0.28 & 1.23 & 4.00 & 6.53 & 17.38 \\
10 & 2.52 & 3.00 & 0.40 & 0.89 & 1.46 & 3.19 & 10.50 \\
\hline 268 & 6.02 & 6.63 & 0.10 & 1.83 & 4.17 & 7.48 & 59.68 \\
\hline
\end{tabular}




\section{Table 4: Revenue Resiliency}

Presented are two sets of revenue resiliency results for the City of Oakland. Columns 1-4 report estimations from the City of Oakland COVID Small Business Survey. The dependent variable is the reported revenue percentage change decline in gross decline, calculated as the natural logarithm of $1+$ percentage change reported YoY for March 2020. We control for the same variable for February to focus on the March crisis impact. The main independent variables are the log of workers (employees +1) and a nonemployer indicator, per the Oakland survey data. In columns 1-2, we include an indicator for the business being main street-facing and one for essential business, both from manual coding. Columns 3-4 add in detailed industry fixed effects, reported below for interest. Robust standard errors in columns 1-4 are in brackets. Columns 5-6 report difference-in-differences estimates of the foot traffic decline for the same businesses in Oakland, including firm and day fixed effects. Standard errors in columns (5)-(6) are clustered by firm in brackets. *,**,and *** indicate significance levels of $10 \%, 5 \%$, and $1 \%$.

\begin{tabular}{|c|c|c|c|c|c|c|}
\hline \multirow{4}{*}{$\begin{array}{l}\text { Dependent Variable: } \\
\text { Log Workers }\end{array}$} & (1) & (2) & (3) & (4) & (5) & (6) \\
\hline & \multicolumn{4}{|c|}{ Log (1+ \% Decline YoY Receipts, March 2020) } & \multicolumn{2}{|c|}{ Log (Foot Traffic) } \\
\hline & $0.0126 * *$ & $0.0274 * * *$ & 0.0099 & $0.0271^{* * *}$ & & \\
\hline & {$[0.00616]$} & {$[0.00895]$} & {$[0.0071]$} & {$[0.0103]$} & & \\
\hline \multirow[t]{2}{*}{ Nonemployer } & & $0.0538 * *$ & & $0.0593^{* *}$ & & \\
\hline & & {$[0.0246]$} & & [0.0261] & & \\
\hline \multirow[t]{2}{*}{ Post } & & & & & $-1.344^{* * *}$ & $-1.193 * * *$ \\
\hline & & & & & {$[0.109]$} & [0.139] \\
\hline \multirow[t]{2}{*}{ Post*Log Workers } & & & & & -0.0673 & $-0.126^{* *}$ \\
\hline & & & & & {$[0.0435]$} & [0.0543] \\
\hline \multirow[t]{2}{*}{ Post*Nonemployer } & & & & & & $-0.334^{*}$ \\
\hline & & & & & & {$[0.192]$} \\
\hline \multirow[t]{2}{*}{ Log Receipts Decline February } & $0.217 * * *$ & $0.225^{* * *}$ & $0.219 * * *$ & $0.231 * * *$ & & \\
\hline & {$[0.0402]$} & {$[0.0403]$} & {$[0.0408]$} & {$[0.0412]$} & & \\
\hline \multirow[t]{2}{*}{ Main Street } & $0.0299 *$ & 0.0274 & 0.0544 & 0.0651 & & \\
\hline & {$[0.0166]$} & {$[0.0167]$} & [0.0799] & [0.0732] & & \\
\hline \multirow[t]{2}{*}{ Essential } & -0.0107 & -0.00738 & 0.00233 & 0.00327 & & \\
\hline & [0.0207] & [0.0201] & [0.0265] & [0.0266] & & \\
\hline \multirow[t]{2}{*}{ Business services } & & & -0.0673 & -0.0842 & & \\
\hline & & & [0.0889] & [0.0835] & & \\
\hline \multirow[t]{2}{*}{ Construction / Manuf / Venue } & & & 0.0059 & -0.00359 & & \\
\hline & & & {$[0.0326]$} & {$[0.0336]$} & & \\
\hline \multirow[t]{2}{*}{ Fitness/gym/wellness } & & & -0.0148 & -0.0302 & & \\
\hline & & & {$[0.0868]$} & {$[0.0812]$} & & \\
\hline \multirow[t]{2}{*}{ Medical Offices } & & & -0.00796 & -0.0187 & & \\
\hline & & & [0.0986] & [0.0923] & & \\
\hline \multirow[t]{2}{*}{ Personal services home } & & & -0.0495 & -0.0728 & & \\
\hline & & & {$[0.0473]$} & [0.0499] & & \\
\hline \multirow[t]{2}{*}{ Personal services shop } & & & -0.0641 & -0.0805 & & \\
\hline & & & [0.0924] & {$[0.0865]$} & & \\
\hline \multirow[t]{2}{*}{ Restaurant } & & & -0.0118 & -0.0367 & & \\
\hline & & & {$[0.0851]$} & {$[0.0798]$} & & \\
\hline \multirow[t]{2}{*}{ Retail } & & & -0.0348 & -0.0477 & & \\
\hline & & & [0.0823] & {$[0.0763]$} & & \\
\hline \multirow[t]{2}{*}{ Salon } & & & -0.0162 & -0.0387 & & \\
\hline & & & {$[0.0847]$} & {$[0.0794]$} & & \\
\hline Firm Fixed Effects & & & & & Yes & Yes \\
\hline Day Fixed Effects & & & & & Yes & Yes \\
\hline Observations & 349 & 349 & 349 & 349 & 23,292 & 23,292 \\
\hline R-squared & 0.107 & 0.120 & 0.125 & 0.139 & 0.796 & 0.797 \\
\hline
\end{tabular}




\section{Table 5: Labor Flexibility - Oakland Survey}

The sample is small business respondents for the City of Oakland COVID Small Business Survey. The dependent variable in columns 1-3 (4-6) is the reported percentage change in full-time (part-time) workers. The main independent variables is the log of workers (employees +1 ). Nonemployer data are not included because of the lack of employees. Included in all columns are an indicator for the business being main street-facing and one for essential business, both from manual coding. Also included is the revenue loss index variable, the combination of standardized firm revenue losses from the gross receipts decline and standardized percentage change in foot traffic by firm. Columns 3 and 6 include this variable interacted with workers. Columns 2,3,5, and 6 add in detailed industry fixed effects. Robust standard errors are in brackets. *,**,and *** indicate significance levels of 10\%, 5\%, and 1\%.

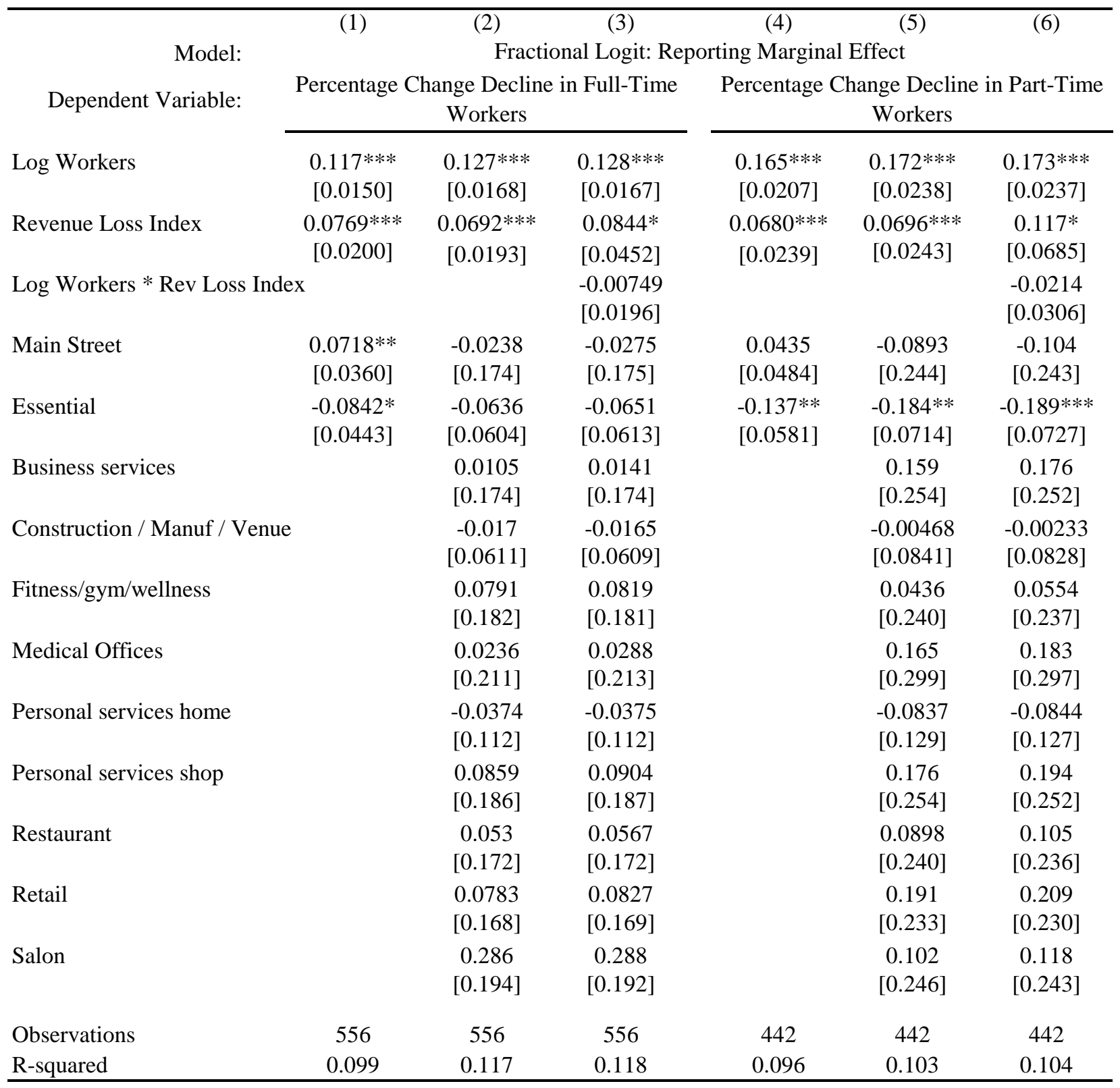




\section{Table 6: Labor Flexibility - Homebase Payroll Data}

The sample is the set of firms in the national Homebase data, matched to the industry-zip code data in SafeGraph. In columns 1-3, the sample is further restricted to the firms in the Oakland area (zip codes 94XXX). Observations are a weekly panel from January 2020 through April 2020. The dependent variable in columns 1-6 is the $\log$ of workers, and in columns 7-9, the log of payroll The main independent variable is the log of workers pre-crisis interacted with post. Firm and week fixed effects are included. Post indicates weeks after March 15, 2020. Log foot traffic is from SafeGraph and is matched to Homebase at the industry-zip code level. Nonemployer data are not included because of the lack of employees. Firm-clustered standard errors are in brackets. *,**, and *** indicate significance levels of $10 \%, 5 \%$, and $1 \%$.

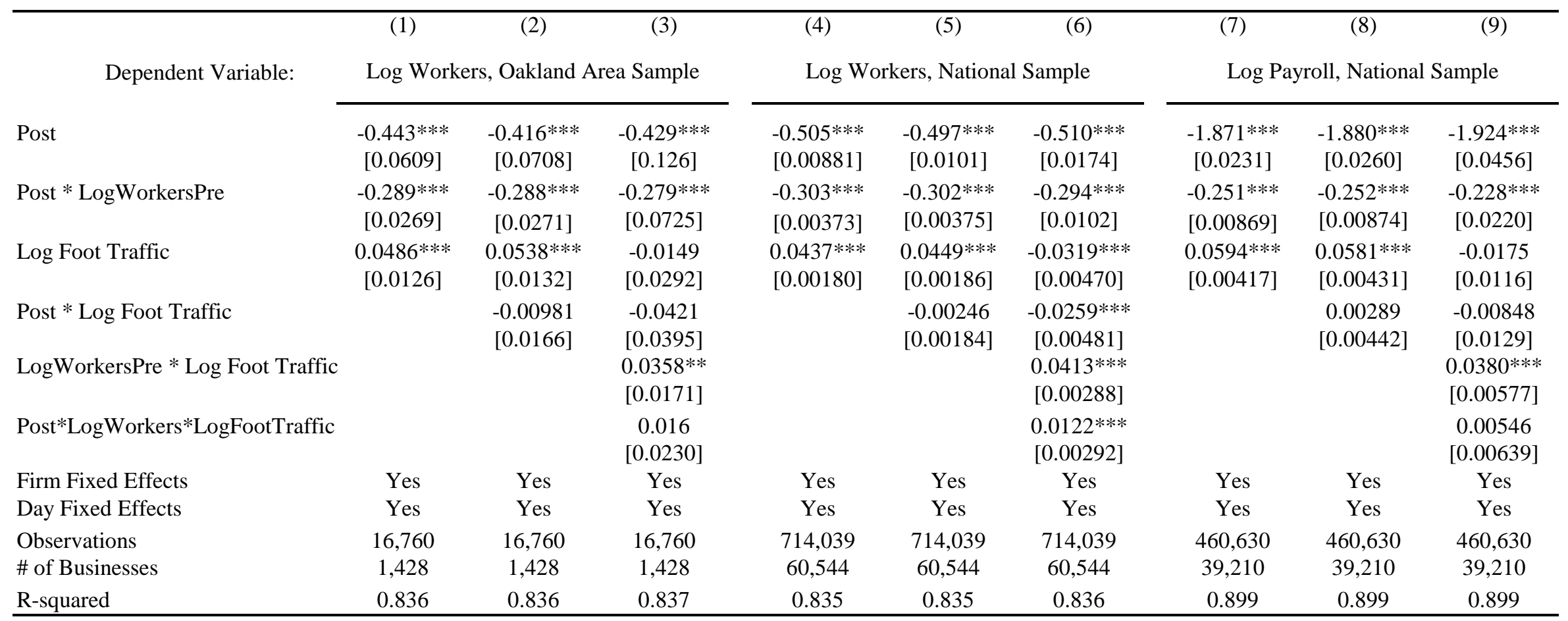




\section{Table 7: Committed Costs Results -- Residual of Closure Risk}

The sample is small business respondents for the City of Oakland COVID Small Business Survey. The dependent variable is the ordinal response of how concerned the business owner is about closure risk: not concerned, somewhat concerned, and very concerned. The is an ordered logit, presenting the log odds ratios (the coefficients) of moving from one category up to the next. We also report the odds ratio, beneath the robust standard errors in brackets for the main independent variable of $\log$ workers (employees +1 ). Included in all columns are an indicator for the business being main street-facing and the percentage change jobs reported. Also included is the revenue loss index variable and whether the business was declining pre-crisis (using the gross receipts YoY for February), and the interim outcome of the business \{Open, Trying, Temporarily Closed, Permanently Closed\}. Columns 3 and 4 are industry random and fixed effects, respectively. (Fixed effects for ordered logit are of questionable consistency; thus we present the random effects as a more reliable estimator.) *,**,and *** indicate significance levels of $10 \%, 5 \%$, and $1 \%$.

\begin{tabular}{|c|c|c|c|c|}
\hline \multirow{2}{*}{$\begin{array}{r}\text { Model: } \\
\text { Dependent Variable: }\end{array}$} & (1) & (2) & (3) & (4) \\
\hline & \multicolumn{4}{|c|}{$\begin{array}{l}\text { Ordered Logit } \\
\text { Closure Risk: Not Concerned }<\text { Somewhat Concerned }<\text { Very Concerned }\end{array}$} \\
\hline Log Workers & $\begin{array}{c}0.251 * * * \\
{[0.0910]} \\
1.285\end{array}$ & $\begin{array}{c}0.195 \\
{[0.128]} \\
1.215\end{array}$ & $\begin{array}{c}0.212^{* *} \\
{[0.105]} \\
1.236\end{array}$ & $\begin{array}{c}0.165^{*} \\
{[0.0975]} \\
1.179\end{array}$ \\
\hline Nonemployer & & $\begin{array}{l}-0.192 \\
{[0.305]}\end{array}$ & & \\
\hline Revenue Loss Index & $\begin{array}{l}0.323 * * * \\
{[0.0947]}\end{array}$ & $\begin{array}{l}0.326^{* * *} \\
{[0.0952]}\end{array}$ & $\begin{array}{c}0.322^{* * *} \\
{[0.117]}\end{array}$ & $\begin{array}{l}0.318^{* * *} \\
{[0.0949]}\end{array}$ \\
\hline Jobs Lost \% Change & $\begin{array}{l}0.774^{*} \\
{[0.462]}\end{array}$ & $\begin{array}{c}0.765 \\
{[0.469]}\end{array}$ & $\begin{array}{l}0.735^{* *} \\
{[0.307]}\end{array}$ & $\begin{array}{c}0.668 \\
{[0.467]}\end{array}$ \\
\hline Interim Outcomes: & & & & \\
\hline Trying & $\begin{array}{l}0.519 * * \\
{[0.261]}\end{array}$ & $\begin{array}{l}0.530^{* *} \\
{[0.263]}\end{array}$ & $\begin{array}{c}0.364 \\
{[0.400]}\end{array}$ & $\begin{array}{c}0.125 \\
{[0.288}\end{array}$ \\
\hline Temporarily Closed & $\begin{array}{c}0.987 * * * \\
{[0.275]}\end{array}$ & $\begin{array}{c}0.986 * * * \\
{[0.275]}\end{array}$ & $\begin{array}{l}0.878 * \\
{[0.469]}\end{array}$ & $\begin{array}{l}0.679 * * \\
{[0.312]}\end{array}$ \\
\hline Permanently Closed & $\begin{array}{l}0.561^{* *} \\
{[0.245]}\end{array}$ & $\begin{array}{l}0.557 * * \\
{[0.245]}\end{array}$ & $\begin{array}{c}0.442^{*} \\
{[0.251]}\end{array}$ & $\begin{array}{c}0.248 \\
{[0.263]}\end{array}$ \\
\hline Declining & $\begin{array}{c}0.879 * * * \\
{[0.187]}\end{array}$ & $\begin{array}{c}0.884 * * * \\
{[0.187]}\end{array}$ & $\begin{array}{c}0.851^{* * *} \\
{[0.195]}\end{array}$ & $\begin{array}{c}0.807^{* * *} \\
{[0.190]}\end{array}$ \\
\hline Main Street & $\begin{array}{l}0.447 * * \\
{[0.218]}\end{array}$ & $\begin{array}{l}0.447 * * \\
{[0.218]}\end{array}$ & $\begin{array}{l}0.452 * * \\
{[0.214]}\end{array}$ & $\begin{array}{l}0.0565 \\
{[1.240]}\end{array}$ \\
\hline Industry Effects & & & random & fixed \\
\hline Observations & 736 & 736 & 736 & 736 \\
\hline R-squared & 0.086 & 0.087 & $\mathrm{n} / \mathrm{a}$ & 0.107 \\
\hline
\end{tabular}


Table 8: City of Oakland Re-opening and Recovery Survey Summary Statistics

Presented are the tabulations of the 278 survey responses from the City of Oakland Re-opening and Recovery Survey.

\begin{tabular}{|c|c|c|c|}
\hline & Count & Percentage & Cumulative \\
\hline Total Oakland Survey Responses & 278 & & \\
\hline \multicolumn{4}{|c|}{ "If business disruption continues at the current rate, how soon will you be at risk of permanently closing your business?" } \\
\hline 0 to 1 month & 26 & 9.4 & 9.4 \\
\hline 1 to 3 months & 85 & 30.6 & 39.9 \\
\hline 3 to 6 months & 71 & 25.5 & 65.5 \\
\hline 6 to 12 months & 55 & 19.8 & 85.3 \\
\hline Never & 41 & 14.8 & 100.0 \\
\hline \multicolumn{4}{|l|}{ Short-Term Closing } \\
\hline Ongoing Concern & 250 & 89.9 & \\
\hline Closed Now or Projected Survival of 0-to-1 month & 28 & 10.1 & \\
\hline \multicolumn{4}{|l|}{ Medium-Run Survival } \\
\hline Surviving & 96 & & \\
\hline Closing & 182 & & \\
\hline \multicolumn{4}{|l|}{ Application Status of Payroll Protection Program (PPP) } \\
\hline Successfully Applied & 148 & 59.4 & 59.4 \\
\hline Unsuccessfully Applied & 45 & 18.1 & 77.5 \\
\hline \multirow[t]{2}{*}{ Not Applied } & 56 & 22.5 & 100.0 \\
\hline & Acceptance Rate & & $77 \%$ \\
\hline \multicolumn{4}{|c|}{ Application Status of Pandemic Unemployment Insurance (PUI) } \\
\hline Successfully Applied & 82 & 32.9 & 32.9 \\
\hline Unsuccessfully Applied & 39 & 15.7 & 48.6 \\
\hline \multirow[t]{2}{*}{ Not Applied } & 128 & 51.4 & 100.0 \\
\hline & Acceptance Rate & & $68 \%$ \\
\hline \multicolumn{4}{|l|}{ Status as of June 2020} \\
\hline Fully Open & 20 & 7.2 & \\
\hline Reduced & 120 & 43.2 & \\
\hline Closed, at least Temporarily & 138 & 49.6 & \\
\hline \multicolumn{4}{|l|}{ Industry } \\
\hline Business Services & 7 & 2.5 & \\
\hline Construction/Industrial/Venue & 18 & 6.5 & \\
\hline Fitness/Salon/Wellness & 59 & 21.2 & \\
\hline Healthcare & 17 & 6.1 & \\
\hline Nonprofit & 15 & 5.4 & \\
\hline Personal Services & 14 & 5.0 & \\
\hline Professional Services & 55 & 19.8 & \\
\hline Restaurant & 61 & 21.9 & \\
\hline Retail & 32 & 11.5 & \\
\hline \multicolumn{4}{|l|}{ Gender Identity } \\
\hline Female & 171 & 61.5 & \\
\hline Male & 74 & 26.6 & \\
\hline Other / Undisclosed & 33 & 11.9 & \\
\hline \multicolumn{4}{|l|}{ Race / Ethnicity } \\
\hline Asian Ethnicity & 48 & 17.3 & \\
\hline Hispanic Ethnicity & 21 & 7.6 & \\
\hline White Race & 120 & 43.2 & \\
\hline Black Race & 31 & 11.2 & \\
\hline Other / Undisclosed / Mixed Race & 58 & 20.9 & \\
\hline
\end{tabular}




\section{Table 9: Selection Tests on Intermediate Outcomes and Actions}

The sample is the dataset of 278 survey responses from the City of Oakland Re-opening and Recovery Survey. The observation count differences across columns comes from fully-determined observations in the estimation, not missing information. Columns 1-2 report an ordered logit estimation of the business status of the firm in June 2020 (closed < reduced operations < open fully). Coefficients are in log odds ratios of moving from any level to the next. Columns 3-10 present logit estimations of the indicator variables listed in the columns, which are answers to the action step question, with marginal effects shown. In addition to the industry effects not shows, the independent variables for each of the PPP and PUI policies are whether the owner applied for the policy, and if so, if successful. Because the full marginal effect of success is applying and succeeding the sum of the marginal effects and its standard error are reported in the lower rows. Robust standard errors are in brackets.

\begin{tabular}{|c|c|c|c|c|c|c|c|c|c|c|}
\hline & \multicolumn{2}{|l|}{$(1)$} & (3) & (4) & (5) & (6) & $(7)$ & $(8)$ & (9) & $(10)$ \\
\hline Model: & \multicolumn{2}{|c|}{ Ordered Logit } & \multicolumn{8}{|c|}{ Logit: Marginal Effects Reported } \\
\hline Question: & \multicolumn{2}{|c|}{ Business Status } & \multicolumn{8}{|c|}{ Action Steps Taken: } \\
\hline Dependent variable: & \multicolumn{2}{|c|}{$\begin{array}{c}\text { Closed }<\text { Reduced } \\
<\text { Open }\end{array}$} & \multicolumn{2}{|c|}{$\begin{array}{l}\text { Furloughed } \\
\text { employees }\end{array}$} & \multicolumn{2}{|c|}{$\begin{array}{c}\text { Having employees } \\
\text { work remotely }\end{array}$} & \multicolumn{2}{|c|}{$\begin{array}{c}\begin{array}{c}\text { Laid off } \\
\text { employees }\end{array} \\
\end{array}$} & \multicolumn{2}{|c|}{$\begin{array}{c}\text { Reduced employee } \\
\text { hours }\end{array}$} \\
\hline Applied PPP & & $\begin{array}{c}-0.738 \\
{[0.460]}\end{array}$ & & $\begin{array}{l}-0.0043 \\
{[0.0831]}\end{array}$ & & $\begin{array}{c}-0.206^{* *} \\
{[0.102]}\end{array}$ & & $\begin{array}{c}0.0359 \\
{[0.0736]}\end{array}$ & & $\begin{array}{c}-0.114 \\
{[0.106]}\end{array}$ \\
\hline Success PPP & $\begin{array}{c}0.373 \\
{[0.282]}\end{array}$ & $\begin{array}{c}0.791 * \\
{[0.413]}\end{array}$ & $\begin{array}{l}0.104^{* *} \\
{[0.0494]}\end{array}$ & $\begin{array}{c}0.111 \\
{[0.0789]}\end{array}$ & $\begin{array}{c}0.0605 \\
{[0.0519]}\end{array}$ & $\begin{array}{l}0.208 * * \\
{[0.101]}\end{array}$ & $\begin{array}{c}0.0178 \\
{[0.0439]}\end{array}$ & $\begin{array}{l}-0.00721 \\
{[0.0655]}\end{array}$ & $\begin{array}{c}0.0526 \\
{[0.0540]}\end{array}$ & $\begin{array}{c}0.131 \\
{[0.0990]}\end{array}$ \\
\hline Applied PUI & & $\begin{array}{c}-0.749 * * \\
{[0.368]}\end{array}$ & & $\begin{array}{c}0.0681 \\
{[0.0705]}\end{array}$ & & $\begin{array}{c}-0.0424 \\
{[0.0697]}\end{array}$ & & $\begin{array}{c}-0.0441 \\
{[0.0764]}\end{array}$ & & $\begin{array}{l}-0.0615 \\
{[0.0931]}\end{array}$ \\
\hline Success PUI & $\begin{array}{c}-1.316^{* * *} \\
{[0.324]}\end{array}$ & $\begin{array}{c}-0.670 \\
{[0.427]}\end{array}$ & $\begin{array}{c}-0.0398 \\
{[0.0544]}\end{array}$ & $\begin{array}{l}-0.0938 \\
{[0.0770]}\end{array}$ & $\begin{array}{c}-0.218^{* * *} \\
{[0.0705]}\end{array}$ & $\begin{array}{c}-0.176 * \\
{[0.0932]}\end{array}$ & $\begin{array}{c}-0.0362 \\
{[0.0560]}\end{array}$ & $\begin{array}{l}-0.00391 \\
{[0.0814]}\end{array}$ & $\begin{array}{c}0.042 \\
{[0.0540]}\end{array}$ & $\begin{array}{c}0.110 \\
{[0.102]}\end{array}$ \\
\hline $\begin{array}{l}\text { Estimate: Applied PPP + Accept PPP } \\
\text { standard error }\end{array}$ & & $\begin{array}{c}0.053 \\
{[0.333]}\end{array}$ & & $\begin{array}{l}0.107 * \\
{[0.055]}\end{array}$ & & $\begin{array}{c}0.002 \\
{[0.070]}\end{array}$ & & $\begin{array}{c}0.029 \\
{[0.057]}\end{array}$ & & $\begin{array}{c}0.016 \\
{[0.058]}\end{array}$ \\
\hline $\begin{array}{l}\text { Estimate: Applied PUI + Accept PUI } \\
\text { standard error } \\
\text { odds ratio }\end{array}$ & & $\begin{array}{c}-1.419 * * * \\
{[0.338]} \\
0.244\end{array}$ & & $\begin{array}{c}-0.026 \\
{[0.056]}\end{array}$ & & $\begin{array}{c}-0.218 * * * \\
{[0.054]}\end{array}$ & & $\begin{array}{c}-0.048 \\
{[0.050]}\end{array}$ & & $\begin{array}{c}0.049 \\
{[0.057]}\end{array}$ \\
\hline Industry Fixed Effects & Yes & Yes & Yes & Yes & Yes & Yes & Yes & Yes & Yes & Yes \\
\hline Observations & 278 & 278 & 278 & 278 & 217 & 217 & 212 & 212 & 194 & 194 \\
\hline Pseudo R-square & 0.170 & 0.186 & 0.097 & 0.100 & 0.163 & 0.189 & 0.060 & 0.063 & 0.106 & 0.119 \\
\hline
\end{tabular}




\section{Table 10: Are PPP and Pandemic Unemployment Insurance Programs Saving Businesses?}

The sample is the City of Oakland Re-opening and Recovery Survey. All estimations are logits, presenting marginal effects. Both dependent variables build off the survey question: "If business disruption continues at the current rate, how soon will you be at risk of permanently closing your business?” The column 1-2 dependent variable, short-term closing, is an indicator equal to 1 if the answer to this question is 0-to- 1 month or if the respondent indicates elsewhere that $\mathrm{s} / \mathrm{he}$ is permanently closed already. The dependent variable in columns 3-4, medium-run surviving, is equal to one if the answer to the question is greater than 6 months. The main independent variables are LogWorkers, equal to the natural log of employees plus 1 (the owner), whether the owner took a PPP, and whether the owner took Pandemic Unemployment Insurance, and the interactions of these program variables with LogWorkers. We control for race, gender identity, industry, and reported company status (closed, trying but reduced, or open). Robust standard errors are in brackets. ${ }^{* * *} \mathrm{p}<0.01,{ }^{* *} \mathrm{p}<0.05,{ }^{*} \mathrm{p}<0.1$

\begin{tabular}{|c|c|c|c|c|c|c|c|c|}
\hline \multirow{3}{*}{$\begin{array}{r}\text { Dependent Variable: } \\
\text { Model: }\end{array}$} & (1) & (2) & (3) & & (4) & (5) & (6) & (7) \\
\hline & \multicolumn{3}{|c|}{ Short-term Closing } & & \multicolumn{4}{|c|}{ Medium-run Surviving } \\
\hline & $\begin{array}{r}\text { Logit } ~ \\
\text { Eff }\end{array}$ & $\begin{array}{l}\text { arginal } \\
\text { cts }\end{array}$ & $\begin{array}{c}\text { Linear } \\
\text { Probability }\end{array}$ & & & Logit Marg & nal Effects & \\
\hline Applied PPP & & $\begin{array}{c}0.0163 \\
{[0.0582]}\end{array}$ & $\begin{array}{c}0.0161 \\
{[0.0629]}\end{array}$ & & & $\begin{array}{c}-0.268^{* * *} \\
{[0.104]}\end{array}$ & $\begin{array}{c}-0.294 * * * \\
{[0.110]}\end{array}$ & $\begin{array}{l}-0.192 * \\
{[0.0989]}\end{array}$ \\
\hline Accept PPP & $\begin{array}{c}0.0573 \\
{[0.0717]}\end{array}$ & $\begin{array}{c}0.0606 \\
{[0.0825]}\end{array}$ & $\begin{array}{c}0.053 \\
{[0.0797]}\end{array}$ & & $\begin{array}{l}0.268 * * \\
{[0.105]}\end{array}$ & $\begin{array}{c}0.473^{* * *} \\
{[0.142]}\end{array}$ & $\begin{array}{c}0.533^{* * *} \\
{[0.150]}\end{array}$ & $\begin{array}{c}0.387 * * * \\
{[0.144]}\end{array}$ \\
\hline Accept PPP * LogWorkers & $\begin{array}{l}-0.0206 \\
{[0.0431]}\end{array}$ & $\begin{array}{c}-0.0232 \\
{[0.0435]}\end{array}$ & $\begin{array}{l}-0.0166 \\
{[0.0206]}\end{array}$ & & $\begin{array}{l}-0.133^{* *} \\
{[0.0540]}\end{array}$ & $\begin{array}{l}-0.139 * * \\
{[0.0561]}\end{array}$ & $\begin{array}{c}-0.185^{* * *} \\
{[0.0586]}\end{array}$ & $\begin{array}{l}-0.129 * * \\
{[0.0569]}\end{array}$ \\
\hline Applied PUI & & $\begin{array}{c}0.0641 \\
{[0.0571]}\end{array}$ & $\begin{array}{c}0.0495 \\
{[0.0619]}\end{array}$ & & & $\begin{array}{l}-0.0344 \\
{[0.0779]}\end{array}$ & $\begin{array}{c}-0.131 \\
{[0.0833]}\end{array}$ & $\begin{array}{c}0.0119 \\
{[0.0789]}\end{array}$ \\
\hline Accept PUI & $\begin{array}{l}-0.168^{* *} \\
{[0.0756]}\end{array}$ & $\begin{array}{l}-0.205^{* *} \\
{[0.0827]}\end{array}$ & $\begin{array}{c}-0.142 * \\
{[0.0819]}\end{array}$ & & $\begin{array}{l}-0.176^{*} \\
{[0.105]}\end{array}$ & $\begin{array}{c}-0.155 \\
{[0.123]}\end{array}$ & $\begin{array}{c}-0.104 \\
{[0.136]}\end{array}$ & $\begin{array}{c}-0.154 \\
{[0.123]}\end{array}$ \\
\hline Accept PUI * Log Workers & $\begin{array}{l}0.164 * * * \\
{[0.0445]}\end{array}$ & $\begin{array}{l}0.159 * * * \\
{[0.0436]}\end{array}$ & $\begin{array}{c}0.129 * * \\
{[0.0505]}\end{array}$ & & $\begin{array}{c}-0.107 \\
{[0.0817]}\end{array}$ & $\begin{array}{c}-0.0861 \\
{[0.0793]}\end{array}$ & $\begin{array}{c}-0.0139 \\
{[0.0813]}\end{array}$ & $\begin{array}{c}-0.0788 \\
{[0.0682]}\end{array}$ \\
\hline LogWorkers & $\begin{array}{l}-0.0162 \\
{[0.0444]}\end{array}$ & $\begin{array}{l}-0.0135 \\
{[0.0452]}\end{array}$ & $\begin{array}{c}0.00343 \\
{[0.0139]}\end{array}$ & & $\begin{array}{l}0.144^{* * *} \\
{[0.0488]}\end{array}$ & $\begin{array}{l}0.158^{* * *} \\
{[0.0506]}\end{array}$ & $\begin{array}{l}0.169 * * * \\
{[0.0523]}\end{array}$ & $\begin{array}{l}0.136 * * * \\
{[0.0508]}\end{array}$ \\
\hline Nonemployers & $\begin{array}{l}-0.0473 \\
{[0.0731]}\end{array}$ & $\begin{array}{l}-0.0501 \\
{[0.0711]}\end{array}$ & $\begin{array}{c}-0.0369 \\
{[0.0626]}\end{array}$ & & $\begin{array}{l}0.185^{*} \\
{[0.106]}\end{array}$ & $\begin{array}{l}0.224 * * \\
{[0.101]}\end{array}$ & $\begin{array}{l}0.247^{* *} \\
{[0.101]}\end{array}$ & $\begin{array}{c}0.183^{*} \\
{[0.105]}\end{array}$ \\
\hline $\begin{array}{l}\text { Fixed Effects Included: } \\
\text { Industry }\end{array}$ & Yes & Yes & Yes & & Yes & Yes & Yes & Yes \\
\hline Gender Identity & Yes & Yes & Yes & & Yes & Yes & Yes & Yes \\
\hline Race/ Ethnicity & Yes & Yes & Yes & & Yes & Yes & Yes & Yes \\
\hline Status & -- & -- & -- & & -- & -- & -- & Yes \\
\hline Action Steps & -- & -- & -- & -- & -- & -- & -- & Yes \\
\hline Drops Furloughing Firms & -- & -- & -- & & -- & -- & Yes & -- \\
\hline Observations & 238 & 238 & 278 & & 278 & 278 & 222 & 278 \\
\hline Pseudo R-square & 0.277 & 0.288 & 0.208 & & 0.210 & 0.237 & 0.279 & 0.268 \\
\hline
\end{tabular}

